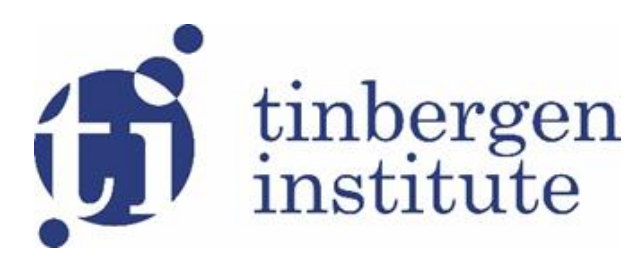

TI 2019-034/VII

Tinbergen Institute Discussion Paper

\title{
Can Collaboration Promote Corporate Social Responsibility? Evidence from the Lab
}

Revision: June 2022

Francisco Gomez Martinez ${ }^{1}$

Sander Onderstal ${ }^{2}$ Marten Pieter Schinke/2,3 
Tinbergen Institute is the graduate school and research institute in economics of Erasmus University Rotterdam, the University of Amsterdam and Vrije Universiteit Amsterdam.

Contact: discussionpapers@tinbergen.nl

More TI discussion papers can be downloaded at https://www.tinbergen.nl

Tinbergen Institute has two locations:

Tinbergen Institute Amsterdam

Gustav Mahlerplein 117

1082 MS Amsterdam

The Netherlands

Tel.: + 31(0)205984580

Tinbergen Institute Rotterdam

Burg. Oudlaan 50

3062 PA Rotterdam

The Netherlands

Tel.: +31(0)10408 8900 


\title{
Can Collaboration Promote Corporate Social
}

\section{Responsibility? Evidence from the Lab ${ }^{a}$}

\author{
Francisco Gomez Martinez, ${ }^{\mathrm{b}}$ Sander Onderstal, ${ }^{\mathrm{c}}$ and Maarten Pieter Schinkel ${ }^{\mathrm{d}}$
}

16 June 2022

\begin{abstract}
Competition has been argued to erode socially responsible behavior in markets, suggesting that allowing collaborative agreements amongst competitors regarding corporate social responsibility (CSR) may promote public-interest objectives. We study this idea experimentally in a duopoly framework in which firms choose between offering a 'fair' and an 'unfair' good to consumers. When the unfair good is traded, a negative externality is imposed on a third party. We vary whether or not the firms are allowed to coordinate on the type of good they sell, while remaining in price competition. Theory predicts the fraction of fair goods traded only to increase when firms care little for the externality yet take the opportunity to collaborate to differentiate their products to soften price competition. We find instead that overall the opportunity to coordinate CSR efforts decreases product differentiation and has no significant impact on the fraction of fair goods traded. Average market prices, producer surplus, and consumer surplus are unaffected. However, third-party preferences are a powerful predictor for both consumer and firm behavior. Product variety does go up if firms' third-party preferences are weak. Our findings suggest that growing consumer and managerial awareness contributes more to socially responsible behavior than opportunities for firms to coordinate their CSR activities. If CSR collaborations are to be allowed, this should be case-specific antitrust policy and not a generic cartel exemption possibility.
\end{abstract}

Keywords: Corporate social responsibility; Sustainability; Collaboration; Antitrust; Laboratory experiment

JEL classification: C92, D03, D62, L41, M14

\footnotetext{
a We received excellent questions, comments, and suggestions on earlier versions of this paper from Björn Bartling, Gary Charness, Juan-Pablo Montero, Wieland Müller, Hans-Theo Normann, Jens Prüfer, Jannika Schad, Adriaan Soetevent, Leonard Treuren, Vanessa Valero, seminar participants at the University of Amsterdam, the University of Newcastle, the University of Nottingham, Radboud University Nijmegen, the Tinbergen Institute workshop on behavioral industrial organization, the Berlin Behavioral Economics Colloquium and Seminar, The Netherlands Authority for Consumers and Markets, the 2017 European ESA meeting (Vienna), the 2019 Asia-Pacific ESA meeting (Abu Dhabi), CRESSE 2019 (Rhodos), EARIE 2019 (Barcelona), and SMS 2020 (Groningen), two anonymous referees and Andreas Lange, the editor. All remaining errors are ours. We gratefully acknowledge financial support from the Research Priority Area Behavioral Economics of the University of Amsterdam.

b Department of Economics, BI Norwegian Business School, Nydalsveien 37, 0484 Oslo, Norway; francisco.g.martinez@bi.no.

c Amsterdam Business School, University of Amsterdam and Tinbergen Institute, Plantage Muidergracht 12, $1001 \mathrm{NL}$, Amsterdam, the Netherlands; onderstal@uva.nl.

d Amsterdam School of Economics, University of Amsterdam and Tinbergen Institute, Roetersstraat 11, 1018 WB, Amsterdam, the Netherlands; m.p.schinkel@uva.nl.
} 


\section{Introduction}

Where government regulation fails, corporate social responsibility (CSR) is an alternative way to curb negative externalities such as from environmental pollution, resource depletion, or unfair business practices. A popular claim is that for companies to be able to effectively take on wider social responsibilities, competitors need to collaborate on their CSR efforts. Kotchen \& Segerson (2019) advocate voluntary collective agreements to solve environmental problems. Henderson (2020) and Polman \& Winston (2021) are recent contributions to a management literature that touts industry-wide and 'pre-competitive' collaboration to stop environmental degradation and economic inequality. Competitive pressure has been argued to erode intrinsically socially responsible behavior in markets in a variety of settings, including in Shleifer (2004), Falk \& Szech (2013), Bartling et al. (2015) and Dewatripont \& Tirole (2022). This suggests that allowing collaborative agreements amongst competitors regarding corporate social responsibility (CSR) may promote public-interest objectives. Practice has gone ahead on this promise, for example in the U.S. Business Roundtable pledge to jointly endorse stakeholder capitalism that would put the interests central of workers, suppliers and communities, including the environment. In Europe, chocolate producers have joined forces to improve their pay to cocoa farmers and garment labels to ban plastics. ${ }^{1}$ End of 2020, the truck manufacturers trade association advertised a joint initiative to phase out diesel engines for electric by $2040 .^{2}$

In this paper, we address the question whether initiatives of corporate collaborations to induce stronger CSR efforts, in restraint of competition, are indeed effective in raising CSR standards. This question is particularly prominent in view of current debates about the extent to which such agreements should be permissible under antitrust law. The pursuit of wider public interests than competition is not a recognized defense under the American antitrust laws. ${ }^{3}$ In Europe, coordinated CSR activities in restraint of trade can be considered for exemption from the anticartel laws. In CECED (1999), the European Commission allowed a horizontal agreement amongst washing machine producers to discontinue their least efficient product lines, based on the argument that it would save on electricity and water use to environmental benefit. ${ }^{4}$ Even though there have been few concrete cases since, the European Commission (2022) has recently added a chapter to its new draft Horizontal Guidelines on rather general conditions under which sustainability agreements could be exempted from the cartel prohibition. Several Member States, including the Netherlands and Austria, have already adopted permissive guidelines and

\footnotetext{
${ }^{1}$ See www.fairtrade-advocacy.org. and www.thefashionpact.org.

2 See www.acea.auto/press-release/all-new-trucks-sold-must-be-fossil-free-by-2040-agree-truckmakers-and-climate-researchers/.

${ }^{3}$ See Werden (2014). Scott (2016) nevertheless points at possibilities to exempt agreements that promote sustainability.

${ }^{4}$ Commission Decision, Case IV.F.1/36.718, CECED, 24 January 1999. See Ahmed and Segerson (2011).
} 
competition law amendments to welcome anticompetitive horizontal agreements with compensating sustainability benefits. ${ }^{5}$

There are also concerns, however, that CSR collaboration may instead induce firms to collude on less CSR than they otherwise would in competition and harm consumers. Schinkel \& Treuren (2021a) review the relevant literature to conclude that the policy presents a risk of abuse and cartel greenwashing. Collusion on reduced CSR efforts has been observed in recent European cartel cases. Part of the agreements in Trucks (2017) concerned a delaying by the manufacturers of the introduction of new engine technology that would have given lower emissions. ${ }^{6}$ Largely the same manufacturers participate in the electric trucks agreement. In Car Emissions (2021), German automakers colluded to limit the effectiveness of the technology to clean exhaust gases emissions in their diesel engine cars. ${ }^{7}$ Coordinated obsolescence has been documented since the beginning of recorded cartel history, in the 1920s Phoebus cartel, in which the participants agreed to reduce the lifespan of lightbulbs (Krajewski, 2014). Instead of competing by differentiating their products as more sustainable, these manufacturers coordinated on offering 'unfair' goods.

We study the impact of CSR collaboration on firms' activities in offering more responsibly produced goods or services, which we refer to as 'fair' - for example CECED and the electric Trucks agreement would be cases of firms coordinating on all offering 'fair' products. Addressed are questions regarding the effects of an opportunity for the firms to coordinate their CSR activities on fair trade, prices, product variety, producer surplus, and consumer surplus, and how these effects may depend on participants' moral values. In a vertical product differentiation model that builds on the Shaked \& Sutton (1982), two firms and a continuum of consumers interact in a three-stage game that we label 'the market game'. In the first stage of the market game, the firms can choose between offering a 'fair' and an 'unfair' good. In the second stage, both firms post a price. In the third stage, consumers can choose between the two offers. When the unfair good is traded, a third party suffers from a negative externality. Consumers and firms care about the negative externality: their utility and profit functions are negatively affected by the unfair good being traded.

To study the effects of CSR collaboration, we examine the impact of allowing firms to reach an agreement regarding the kind of good (fair or unfair) that each firm will offer in the first stage of the market game. They can do so on the basis of a coordination mechanism based on alternatingoffers negotiation. We identify parameters in our model for which CSR collaboration: (i) increases the likelihood that the fair good is traded, (ii) increases product variety, when the firms do not

\footnotetext{
${ }^{5}$ See ACM (2021). For a critical discussion of these policy initiatives, see Schinkel and Treuren (2021a).

${ }^{6}$ Trucks (2017). Commission decision, Case AT.39824 - Trucks, September 27.

${ }^{7}$ Car Emissions (2021), Commission Decision, Case AT.40178 - Car Emissions, July 8.
} 
care about the negative externality and therefore both produce the unfair good in competition, in which case coordination allows them to profitably product differentiate, (iii) has an upwards effect on prices for the fair good and the unfair good, (iv) increases producer surplus, and (v) decreases consumer surplus. These findings suggest that policy makers considering to encourage fair trade by allowing CSR collaboration should be cautious of detrimental effects and aware of the particular circumstances under which it may and may not work.

To prospect whether allowing CSR collaboration is empirically sound policy for its purpose, we conducted three laboratory experiments. Our experiments closely follow the experimental paradigm developed by Bartling et al. (2015) to study socially responsible behavior in markets. Participants playing the role of firms choose between offering a fair and an unfair good to a consumer participant, where they could or could not coordinate on the kind of goods offered, depending on the treatment. After that, the firms compete in prices. Trade of the unfair good imposes a negative externality on a third party. Each experiment consists of two treatments. In treatment COORDINATION, participants interacted in the coordination mechanism before playing the market game. In treatment No COORDINATION, the participants interacted in the market game right away. Comparing the outcomes in COORDINATION and No COORDINATION allows us to identify the effects of CSR collaboration on fair trade, prices, product variety, producer surplus, and consumer surplus. Before participants interacted in the market games, we measured the extent to which they care about the externality imposed on the third party on the basis of a variant of Yang et al.'s (2016) social-preferences test.

Laboratory experiments are a natural first research method to address questions in environmental and resource economics in general, and about the effects of novel policy in particular (Kube et al., 2018). This is certainly so for testing the policy proposals to grant exemptions to coordinate on sustainability efforts, which have not been implemented yet, so that field data is not available. If the desired effects are not observed in the laboratory, particularly in settings where economic theory predicts they will occur, there may be reason to rethink the policy implementation, and have reservations about its enforcement and the desired effects taking place in practice (Schram, 2005; List, 2020). Cartel behavior is more readily studied in the lab than in the field in general, because of its (potentially) illegal nature. Moreover, in the laboratory it is easier to measure and control for several variables of interest for the effectiveness of a policy, in this case including consumer demand and preferences for the externality. Our experimental setup allows us to study how the outcome measures are affected by the participants' values about third-party harm.

The theory predicts that CSR collaboration increases the fraction of fair goods traded. The reason is a firm that cares little about the externality offers the unfair good in competition, in the 
expectation to compete against an intrinsically motivated firm that offers the fair good. When two firms that do not internalize the externality can collaborate, they take the opportunity to coordinate to differentiate their products to reduce price competition. When one or both firms have sufficiently strong social preferences, the policy has no effect on CSR: in competition either the firms already offer different product types, or they both offer the fair good, in which case CSR collaboration does not change the product offers. Overall, therefore CSR collaboration is predicted to increase the fraction of fair goods traded in a population with a full spectrum of social preferences, including in particular unconditionally selfish firms. These theoretical findings can already inform the debate on collaborative CSR.

Our experimental findings produce mixed support for these predictions. We find that CSR collaboration has no significant impact on the overall fraction of fair goods traded, average market prices, producer surplus, and consumer surplus. Instead CSR collaboration leads not to more product differentiation but to more symmetric offers, i.e, the firms coordinate on offering more of the same type of good (fair or unfair), thus decreasing product variety. Consistent with the theory, however, the more a consumer cares about the third party, the more likely she is to avoid the externality either by buying the fair good if one is offered or by not buying at all. Similarly, the likelihood of firms offering the fair good instead of the unfair good depends positively on firms' third-party preferences. Moreover, we also find some support in the data that the opportunity to coordinate helps firms with weak third-party preferences to differentiate their products more frequently, i.e. for the mechanism that could make the policy work in theory. That the overall effects of CSR collaboration turns out to be negligible in the entire sample does not support a broad cartel exemption possibility for CSR collaboration. Yet targeted anticompetitive collaboration amongst firms that do not care for CSR intrinsically may increase CSR efforts - albeit potentially at the expense of consumers.

The remainder of this paper is organized as follows. In Section 2, we outline how our paper relates to previous literature. Our theoretical predictions are in Section 3. Section 4 includes our experimental results. In Section 4.1, we present our baseline experiment in which the third party suffering from a negative externality in the event of the unfair good being traded is a participant in the laboratory. The results are in Section 4.2. Sections 4.3 and 4.4 contain designs and results from two additional experiments aimed at establishing robustness of our experimental findings. In one, the externality is more diffused: trading the unfair good creates a carbon-emission into 'the world'. In the other experiment, the firms can only coordinate on both selling the fair good. With some notable exceptions, the findings in both additional experiments are qualitatively in line with the ones in the baseline experiment. Section 5 concludes. Proofs of propositions are in Appendix A.1. 


\section{Related literature}

Our paper contributes to two large but largely separate literatures, on CSR and competition policy respectively. Their overlap points to ambiguous effects of market competition on CSR. Bénabou \& Tirole (2010) discuss various reasons why firms may act responsibly, ranging from pure profit to intrinsic motivations. When CSR is a for-profit differentiation strategy, as in Baron (2001), McWilliams \& Siegel (2001) and Porter \& Kramer (2006), the response to stronger competition would be more CSR. Several empirical studies find support for this claim. Fernández-Kranz \& Santaló (2010) observe that firms in more competitive U.S. industries invest more in CSR activities. Zhang et al. (2010), using data from Chinese firms, find that corporations that spend more on advertising tend to donate more to charity, and more so in highly competitive markets. Du et al. (2011) report on a case of CSR as a challenger's competitive weapon against a market leader. Flammer (2015) sees an increase in CSR activities with increased competition following import tariff reductions. Simon \& Prince (2016) observe that competition reduces toxic pollution releases at the facility level. Using data from over 7,000 firms in 25 countries, Aghion et al. (2022) find that market competition enhances the positive effect of consumers' pro-environment attitudes on green innovation. In experimental markets, Pigors \& Rockenbach (2016) find that when competition is introduced, socially responsible behavior is profit enhancing.

On the other hand can market competition have a negative impact on CSR when increased market competition crowds out intrinsically motivated moral behavior. Shleifer (2004) gives examples of the need to cut cost in competition crowding out intrinsically motivated moral behavior. Roth et al. (1991) find evidence that increased competition leads to fewer 'fair' outcomes in the lab. Falk \& Szech (2013) and Bartling et al. (2015) observe that intrinsic CSR behavior may be eroded in experimental markets. In Ziegler et al. (2020) firms being able to sell more units of a good exhibiting a negative externality has a negative impact on moral behavior in the lab. Cai \& Liu (2009) report that firms in more competitive markets engage in more tax avoidance activities in China. Duanmu et al. (2015) find lower environmental performance amongst Chinese firms that are exposed to intensified competition as well. Markussen \& Røed (2017) and Brekke et al. (2019) observe that general practitioners in Norway are more lenient gatekeepers of public healthcare, the more competitive the market for their services is. Lee et al. (2018) observe less CSR activity in the more competitive markets in South Korea.

The suggestion that collaboration amongst competitors would stimulate CSR efforts finds little support in the literature. That increased market power can reduce externalities through volume effects from price increases, as famously pointed out by Solow (1974), has been studied in various markets. Adler (2004), for example, argues that a cartel of fishermen conserves the environment. Colombo \& Labrecciosa (2018) show that cooperation between firms in a natural resource 
oligopoly may enhance resource stock. Yet Maxwell et al. (2000), Alberini \& Segerson (2002) and Lyon \& Maxwell (2004) are critical of self-regulation and collaboration in voluntary agreements amongst competitors. Analyzing CSR efforts theoretically, Schinkel \& Spiegel (2017) and Schinkel \& Treuren (2021b) establish that the coordination of product standards reduces incentives to invest in greener products, despite consumers' willingness to pay for them. These papers analyze symmetric equilibria, so that the firms cannot take the opportunity to make sustainability agreements to differentiate their products on the CSR dimension.

We contribute to the debate on whether competition or collaboration stimulates CSR efforts by studying the effects of CSR agreements amongst competing firms in two ways. First, we model coordination on product type as a vertical product differentiation strategy, building on Shaked \& Sutton (1982) and Kurtyka \& Mahenc (2011). Second, we study the effects of CSR collaboration in laboratory experiments. As far as we are aware, this has not been done before. The experimental literature on cooperation between firms has mainly focused on cooperation regarding price, quantity, and market entry. Recent examples include Fonseca \& Normann (2012), Gomez-Martinez et al. (2016), and Hinloopen et al. (2020). For an overview, see Potters \& Suetens (2013). An important lesson from that literature is that the ability to make agreements makes markets less competitive at the expense of consumers. This is one motivation for us to only allow firms to coordinate their CSR activities - which is the only type of collaboration for which the policy aims to provide an exemption from the cartel prohibition. Bartling et al. (2015), on which we base our experiments, does not consider collaboration amongst competitors.

This paper also contributes to the literature on consumer and managerial values. Engelmann et al. (2018) provide evidence that participants that act socially responsibly in experimental markets also reveal a preference for a fair-trade chocolate bar over a conventional one. Managerial values are studied in the classic 'upper echelons perspective' in the management literature that goes back to Hambrick \& Mason (1984) and that has a solid empirical basis. For example, Agle et al. (1999) observe significant relationships between CEO values and corporate social performance. Chin et al. (2013) report that firms with liberal CEOs exhibit greater advances in CSR than firms with conservative CEOs. Marquis \& Lee (2013) find that the presence of female senior managers positively affects corporate philanthropic contributions. Filistrucchi \& Prüfer (2019) identify differences in strategic decisions between Catholic and Protestant nonprofit hospitals. Such evidence supports the external validity of laboratory experiments, like ours, in which the effect of managerial values on socially responsible behavior in markets is studied. 


\section{Theory and hypotheses}

To identify settings in which CSR collaboration motivates firms to increase their CSR efforts, we extend the vertical product differentiation model in Shaked \& Sutton (1982) by allowing firms to partly internalize external effects of their products by collaborating on their CSR efforts to produce a 'fair' product. We follow Kurtyka \& Mahenc (2011) by modelling a product's negative externality as a vertical attribute. That is, we consider a market consisting of two firms and one representative (female) consumer. The firms and the consumer interact in the following threestage game ('the market game').

1. The firms simultaneously and independently choose whether to produce a fair good or an unfair good. The firms' decisions become common knowledge.

2. The firms simultaneously and independently set a weakly positive price.

3. The consumer buys at most one of the goods offered in the market. She can also decide not to buy at all.

We analyze the following 'collaboration game' to study the effect of CSR collaboration, where we assume that the firms can only coordinate on the kind of products offered, not on the prices which is in line with the policy proposals discussed in the introduction.

1. One firm is randomly chosen to become the first proposer. This firm makes a proposal that states the kind of good each firm will offer.

2. The other firm can accept or reject the proposal. If the proposal is accepted, proceed to stage 6.

3. The other firm makes a proposal that states the kind of good each firm will offer.

4. The first firm accepts or rejects the proposal. If the proposal is accepted, proceed to stage 6.

5. The firms simultaneously and independently choose whether to produce a fair good or an unfair good. The firms' decisions become common knowledge.

6. The firms simultaneously and independently set a weakly positive price.

7. The consumer buys at most one of the goods offered in the market. She can also decide not to buy at all.

Comparing the outcomes between the market game and the collaboration game allows us to make predictions regarding the effects of CSR collaboration that we measure in our experiments. 
The consumer is characterized by her preference parameter $\gamma$ that measures how much utility she loses when buying the unfair good compared to buying the fair good. We assume that $\gamma$ is uniformly distributed over the interval $[0, \bar{\gamma}] .{ }^{8}$ A consumer of type $\gamma^{\prime}$ s utility equals

$$
U_{\gamma}=\left\{\begin{array}{cl}
0 & \text { if the consumer does not buy } \\
v-p & \text { if she buys the fair good at price } p \\
v-p-\gamma & \text { if she buys the unfair good at price } p
\end{array}\right.
$$

where $v$ is the good's consumption value, which is assumed to be the same for the fair good and the unfair good. The consumer's utility when not buying equals 0 . The interpretation is that trade of the unfair good imposes a negative externality on a third party which decreases consumer type $\gamma$ 's utility by $\gamma$. In other words, $\gamma$ is the consumer's 'moral costs' of buying the unfair good. The fair good is 'socially responsible' in that it does not result in a negative externality. Notice that the consumer can also avoid the negative externality by not buying any product.

Firm $i$ 's marginal costs when selling the [un]fair good equal $c^{f}, 0<c^{f}<\bar{\gamma}\left[c^{u}, 0 \leq c^{u} \leq c^{f}\right]$. Firm $i$ is characterized by a parameter $\varphi_{i}, i=1,2$, which could be interpreted as the extent to which firm $i$ incorporates the negative externality imposed by the unfair good being sold into its profit function, i.e., firm $i$ 's profit equals

$$
\pi_{i}=\left\{\begin{array}{cl}
-\varphi_{i} 1\{\text { the unfair good is traded }\} & \text { if firm } i \text { does not sell } \\
p-c^{f} & \text { if firm } i \text { sells the fair good at price } p \\
p-c^{u}-\varphi_{i} & \text { if firm } i \text { sells the unfair good at price } p
\end{array}\right.
$$

where $1\{X\}$ denotes the indicator function of an event $X$. The parameters $\gamma$ and $\varphi_{i}$ are naturally interpreted as consumer and managerial values respectively. We assume that the $\varphi_{i}$ 's are private information and that they are independently drawn from the set $\{0, \bar{\varphi}\}$ where $\bar{\varphi}>0$ and $P\left\{\varphi_{i}=\bar{\varphi}\right\}=\alpha \in(0,1)$.

To assure the existence of a pure-strategy equilibrium, we make the following additional assumptions:

$$
\begin{aligned}
& \text { (A1) } v>\frac{2 c^{f}+c^{u}+2 \bar{\gamma}}{3} \\
& \text { (A2) } \frac{2}{5}\left(\bar{\gamma}+c^{f}-c^{u}\right) \leq \bar{\varphi} \leq \bar{\gamma}+c^{f}-c^{u} \\
& \text { (A3) } \alpha \geq \underline{\alpha} \equiv \frac{\left(4 \bar{\gamma}-2\left(c^{f}-c^{u}\right)-\bar{\varphi}\right)^{2}}{\left(4 \bar{\gamma}-2\left(c^{f}-c^{u}\right)-\bar{\varphi}\right)^{2}+4\left(\bar{\gamma}+c^{f}-c^{u}-\bar{\varphi}\right)^{2}}
\end{aligned}
$$

\footnotetext{
${ }^{8} \mathrm{An}$ alternative interpretation of the model is that there is a population of consumers of mass 1 that is uniformly distributed over the interval $[0, \bar{\gamma}]$.
} 
Assumption A1 expresses that the consumer value of the good should be sufficiently great, guaranteeing that the consumer always buys in equilibrium - i.e. actually is a consumer in the meaning of the competition law. By Assumption A2 the firms internalize the negative externality imposed by the unfair good experience an intermediate large disutility from the unfair good being traded. Assumption A3 states that a sufficiently large fraction of the firms 'care' about the negative externality.

Let $p_{i}$ denote firm $i$ 's equilibrium price, $i=1$,2. Proposition 1 shows that under assumptions A1A3, the market game has a separating Bayesian perfect equilibrium in which firms for which $\varphi_{i}=$ 0 ('type-0 firms') offer the unfair good and firms for which $\varphi_{i}=\bar{\varphi}$ ('type- $\bar{\varphi}$ firms') offer the fair good.

Proposition 1. Under Assumptions A1-A3, the market game has a symmetric Bayesian perfect equilibrium in which:

(i) Firm i produces the [un]fair good if $\varphi_{i}=\bar{\varphi}\left[\varphi_{i}=0\right], i=1,2$.

(ii) If both firms produce the unfair good, $p_{1}=p_{2}=c^{u}$.

(iii) If both firms produce the fair good, $p_{1}=p_{2}=c^{f}$.

(iv) Iffirm i produces the fair good and firm $j \neq i$ produces the unfair good, firm $i$ 's and firm j's equilibrium prices are

$$
\begin{gathered}
p_{i}=p^{f}(\bar{\varphi}) \equiv \frac{2 c^{f}+c^{u}-2 \bar{\varphi}+2 \bar{\gamma}}{3}>c^{f} \\
p_{j}=p^{u}(\bar{\varphi}) \equiv \frac{c^{f}+2 c^{u}-\bar{\varphi}+\bar{\gamma}}{3}>c^{u}
\end{gathered}
$$

respectively.

If both firms offer the same type of good, price competition makes that their prices are equal to marginal cost of producing that type. In the case of product differentiation, the equilibrium price for the unfair good will be higher than marginal costs. Assumptions $\mathbf{A 2}$ assures that both firms sell a strictly positive quantity at the proposed equilibrium prices. Moreover, the lower-bound for $\bar{\varphi}$ in Assumption $\mathbf{A} 2$ guarantees that type- $\bar{\varphi}$ firms have no reason to deviate from the equilibrium and offer an unfair good instead: offering the unfair good at a price sufficiently low to attract any consumers results in a negative payoff for $\bar{\varphi}$ sufficiently great. Assumption $\mathbf{A} \mathbf{3}$ is necessary and sufficient to prevent type-0 firms from deviating and selling a fair good instead of an unfair good. For a type- 0 firm, selling a fair good instead of an unfair good is unattractive only if it is sufficiently likely to face competition from a type- $\bar{\varphi}$ firm offering the fair good, i.e., $\alpha$ should be sufficiently large. For lower values of $\alpha$, the equilibrium is in mixed strategies, where a type-0 firm 
randomizes between selling the unfair good and the fair good. In Appendix A. 2 we derive such mixed-strategy equilibrium for the case where $\alpha=0$.

We now turn to the collaboration game. Proposition 2 presents a symmetric equilibrium under the assumptions considered plus the following additional assumption:

(A4) $\bar{\varphi} \geq(4-\sqrt{12}) \bar{\gamma}-(2+\sqrt{12})\left(c^{f}-c^{u}\right)$,

which assures that a second-mover type-0 has no reason to reject a first mover's fair-unfair proposal.

Proposition 2. Under Assumptions A1-A4, the following strategies constitute a Bayesian perfect equilibrium of the collaboration game:

(i) When it is a type-0 firm's turn to make a proposal, it proposes offering the fair good itself and the other firm offering the unfair good

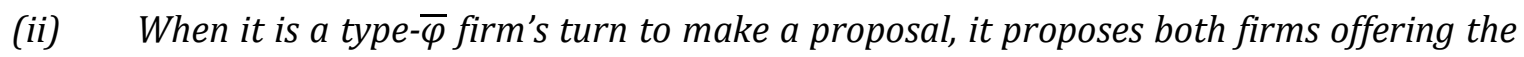
fair good.

(iii) A type- $\bar{\varphi}$ firm accepts proposals according to which it offers the fair good; it rejects any other proposal. A type-0 firm accepts proposals according to which it offers the unfair good and the other firms offers the fair good; it rejects any other proposal.

(iv) If a proposal is accepted in the first stage according to which the two firms offer a different kind of good, the firm offering the [un]fair good chooses price $p^{f}(0)\left[p^{u}(0)\right]$ displayed in equations (A.8) and (A.9) in Proposition 1.

(v) If a proposal is accepted in the second stage according to which the two firms offer a different kind of good, the firm offering the [un]fair good chooses price $p^{f}(\bar{\varphi})\left[p^{u}(\bar{\varphi})\right]$ displayed in equations (A.8) and (A.9) in Proposition 1.

(vi) If a proposal is accepted according to which both firms offer the [un]fair good, both firms choose price $p_{i}=c_{f}\left[p_{i}=c_{u}\right]$.

(vii) If both proposals are rejected, the firms play according to the equilibrium of the market game displayed in Proposition 1.

Proposition 2 shows that the collaboration game allows a pair of type- 0 firms to differentiate their goods, while any other realization of types $(0, \bar{\varphi}$ or $\bar{\varphi}, \bar{\varphi})$ results in the same outcome as in the market game. Because types are perfectly revealed in the coordination mechanism, when two type-0 firms interact, they differentiate their products to escape head-on price competition to charge equilibrium prices above marginal costs. A type- 0 firm and type- $\varphi$ firm paired in competition already product differentiated, so they cannot benefit from product type coordination. When two type- $\varphi$ firms are present, neither firm has a reason to deviate from the agreement to both offering a fair good, because of the negative utility incurred from selling the 
unfair good. Notice that in equilibrium, initial proposals are sometimes rejected, e.g., a type-0 firm will reject a type- $\bar{\varphi}$ firm's proposal that both firms offer the fair good. As a result, the second proposal stage is required to enhance collaboration.

We are interested in the effects of CSR collaboration on socially responsible behavior, product quality, consumer surplus, and producer surplus. How does CSR collaboration change the outcomes of the market game and the extended market game? Table 1 presents the main differences between the market game and the collaboration game in terms of equilibrium outcomes.

Table 1: Equilibrium outcomes of the market game and the collaboration game under Assumptions A1-A4

\begin{tabular}{lcccc}
\hline Firm types & \multicolumn{2}{c}{ Goods traded } & \multicolumn{2}{c}{ Prices } \\
& Market & Collaboration & Market & Coll. \\
\hline$\varphi_{1}=\varphi_{2}=0$ & Only unfair & Fair and unfair & $c^{u}, c^{u}$ & $p^{f}(0)$, \\
& & & & $p^{u}(0)$ \\
$\varphi_{1}=\varphi_{2}=\bar{\varphi}$ & Only fair & Only fair & $c^{f}, c^{f}$ & $c^{f}, c^{f}$ \\
$\left\{\varphi_{1}, \varphi_{2}\right\}=\{\bar{\varphi}, 0\}$ & Fair and unfair & Fair and unfair & $p^{f}(\bar{\varphi})$, & $p^{f}(\bar{\varphi})$, \\
& & & $p^{u}(\bar{\varphi})$ & $p^{u}(\bar{\varphi})$ \\
& & & & \\
\hline
\end{tabular}

Hence, the two regimes only differ in terms of the product type offered if both firms are of type0 . In this case, when both firms do not care about the externalities they produce, they offer the unfair product in competition and take the opportunity to collaborate for profitable product differentiation. For all other type- $\varphi$ values, being allowed to coordinate their product types does not change what product types are being offered. If both firms have sufficiently strong social preferences, they offer the fair goods only, whereas asymmetric type matches lead to similar expected mixes of fair and unfair products. It follows that CSR collaboration has a positive effect on the fraction of fair goods traded and product variety, through the share of type- 0 firms in the economy, i.e. the producers least intrinsically motivated to produce socially responsibly.

Proposition 3 summarizes these results, and includes the observation that CSR collaboration has a negative effect on consumer surplus. The latter result is not trivial, as the increased prices that consumers pay should be traded off against the greater product variety benefitting them in compensation. 
Proposition 3. Under Assumptions A1-A4, CSR collaboration

(i) increases the likelihood that the fair good is traded;

(ii) increases product variety;

(iii) has a positive effect on prices for the fair good and the unfair good;

(iv) increases producer surplus;

(v) decreases consumer surplus.

In Appendix A.2 we show that Proposition 3 also holds true outside the parameter space implied by Assumptions A1-A4. There we find that if $\alpha=0$, i.e., if neither firm internalizes the negative externality, the market game has a symmetric mixed-strategy equilibrium, in which both firms randomize over offering the fair good and the unfair good. In contrast, the collaboration game has a pure-strategy equilibrium in which the firms always differentiate their goods: one offers the fair good and the other offers the unfair good. The effects of CSR collaboration are the same as articulated in Proposition 3.

These findings allow us to formulate the following hypotheses that we will test using our baseline experiment and two variations for robustness.

Hypothesis 1. CSR collaboration increases the fraction of fair goods traded.

Hypothesis 2. CSR collaboration increases product variety.

Hypothesis 3. CSR collaboration (a) increases the prices for both fair and unfair goods, (b) increases producer surplus, and (c) decreases consumer surplus.

The model also reveals that these effects stem in particular from heterogeneity in consumer and managerial values. This translates into the following additional testable hypotheses.

Hypothesis 4. The more the consumer cares about the externality, the more likely she is to buy the fair good.

Hypothesis 5. A firm is more likely to offer the fair good, the more it cares about the externality.

Hypothesis 6. CSR collaboration induces firm that do not internalize the externality to differentiate their products.

Hypothesis 7. The likelihood of both firms offering the fair good is unaffected by CSR collaboration regardless of how much the firms care about the externality. 


\section{Collaborative CSR Experiments}

Given the novelty of the policy proposed, so that cases and empirical data is lacking, and the importance of third-party preferences highlighted in our theoretical analysis, we employ laboratory experiments to test our hypotheses. These experiments allow us to study whether collaboration can increase CSR when participants care to varying degrees about reducing negative production externalities. We ran three experiments at the CREED laboratory of the University of Amsterdam (UvA). In each, two participants were given the role of firm deciding to offer a 'fair' or 'unfair' good, and one participant that of the consumer buying one (or none) of the goods offered. In the baseline experiment, a fourth participant was the third party suffering from the negative externality of an unfair good being traded. Two additional experiments are designed to establish robustness. In the first, the externality is more diffused, as a carbon-emission into 'the world'. In the second experiment, the firms are only able to coordinate on both selling the fair good.

\subsection{Experimental Design and Procedures}

In total, 368 participants took part in one of the experimental sessions: 136, 96 and 136 in Experiments 1, 2 and 3 respectively. In the econometric analysis performed in the results sections, following Bartling et al.'s (2015) procedure, we control for individual random effects with robust standard errors clustered by participant. We will report the results for each experiment separately. In Appendix B, we show that, by and large, an analysis based on the pooled data produces qualitatively the same results regarding our main hypotheses.

The experiments were computerized and programmed in PHP/mySQL. We used control questions to test the participants' understanding of the instructions. ${ }^{9}$ Payoffs in the experiments were denominated in 'francs.' The exchange rate was 1 euro for 10 francs. Each session lasted between 60 and 90 minutes. At the beginning of each session, participants were informed that the experiment consisted of two parts, and that the instructions to each part would be distributed at the start of that part. In part 1, we measured participants' 'third-party preferences' using a variant of a social preferences test developed by Yang et al. (2016) (see Table 2). The participants were randomly assigned into pairs. Each participant made 10 choices between options A and B. Each choice determined the payoffs for both the decision-maker and the participant she was paired with (the receiver). One of the 10 decisions in part 1 or one of the 24 market rounds in part 2 (to be discussed below) was randomly chosen to determine payment at the end of a session. If one of the decisions in part 1 was chosen to determine payments at the end of a session, in each

\footnotetext{
9 The instructions are in Appendix C.
} 
pair one of the participants was appointed decision-maker and his/her decision for the selected choice was implemented.

Table 2: The 10 choices in part 1

\begin{tabular}{lllc}
\hline Nr. & Option A & Option B & Choose B iff \\
\hline 1 & Yours: 125; Other's: 80 & Yours: 130; Other's: 0 & $\gamma \leq 4.375$ \\
2 & Yours: 120; Other's: 80 & Yours: 130; Other's: 0 & $\gamma \leq 8.75$ \\
3 & Yours: 115; Other's: 80 & Yours: 130; Other's: 0 & $\gamma \leq 13.125$ \\
4 & Yours: 110; Other's: 80 & Yours: 130; Other's: 0 & $\gamma \leq 17.5$ \\
5 & Yours: 105; Other's: 80 & Yours: 130; Other's: 0 & $\gamma \leq 21.875$ \\
6 & Yours: 100; Other's: 80 & Yours: 130; Other's: 0 & $\gamma \leq 26.25$ \\
7 & Yours: 95; Other's: 80 & Yours: 130; Other's: 0 & $\gamma \leq 30.625$ \\
8 & Yours: 90; Other's: 80 & Yours: 130; Other's: 0 & $\gamma \leq 35$ \\
9 & Yours: 85; Other's: 80 & Yours: 130; Other's: 0 & $\gamma \leq 39.375$ \\
10 & Yours: 80; Other's: 80 & Yours: 130; Other's: 0 & $\gamma \leq 43.75$ \\
\hline
\end{tabular}

Notes: The 10 decisions between options A and B. "Yours" refers to the decision-maker's payoff and "Other's" to the receiver's payoff. The final column presents the values of $\gamma$ that rationalize a choice of option B for a participant whose utility function is represented by Eq. (3). This column was obviously not shown to the participants.

We estimate participant's third-party preferences assuming that their utility function is given by

$$
u(x, z)=x+\frac{\gamma}{70} z
$$

where $x$ is the own payoff and $z$ is the other's payoff. We have normalized the utility function in such a way that under the experimental parameters of market game (to be discussed next), $\gamma$ can be interpreted as the highest price difference between the fair good and the unfair good for which the consumer would prefer to buy the fair good over the unfair good. ${ }^{10}$ Under the assumption that participants' decisions are consistent between the market and non-market environments, participants' decisions in part 1 of the experiments allow us to measure $\gamma$. More precisely, the point where participants switch from option A to option B identifies the interval in which $\gamma$ lies. ${ }^{11}$ For example, if a participant chooses option A in decisions 1-4 and option B from decision 5 onwards, then $\gamma \in(17.5,21.875]$. Figure 1 plots the cumulative distribution of the switching points in the three experiments.

\footnotetext{
${ }^{10}$ Notice that in all 10 options A and B in table 2, the decision-maker earned more than the other person. Therefore, the test could also be used to measure $\beta$ in the Fehr and Schmidt (1999) model according to which the decision-maker's utility is given by $\tilde{u}(x, z)=x-\beta(x-z)$ for $z \leq y$. Indeed, model (3) is equivalent to the Fehr-Schmidt model for $z \leq y$ if $\beta=\frac{\gamma}{70+\gamma}$.

11 With consistent preferences, some consumers may always choose the altruistic option, others would always choose the selfish option, and the rest would switch from the altruistic option to the selfish option at some point and keep choosing the selfish option until the last dictator decision. We refer to other choice patterns as 'inconsistent preferences'. In the three experiments, 25 participants exhibited inconsistent preferences $(6.7 \%$ of our participants). We excluded these participants' decisions from the analysis requiring third-party preferences.
} 
Figure 1: Cumulative distribution of switching points in Part 1

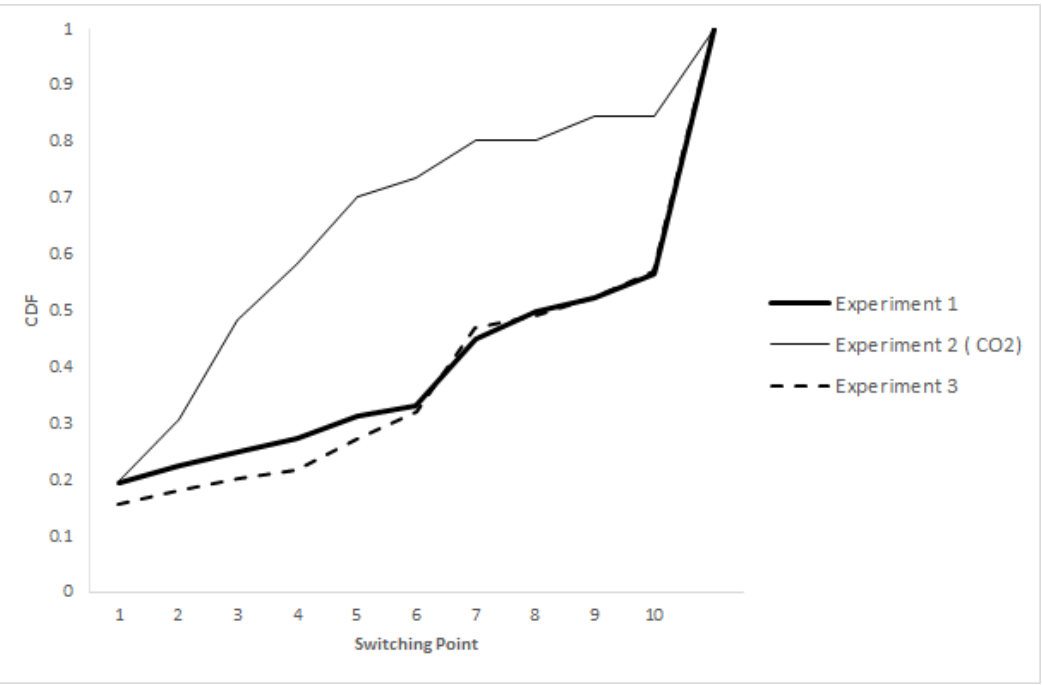

In part 2, participants interacted in the one-shot market game for 24 rounds in a variant of the experimental paradigm introduced by Bartling et al. (2015). In each round, participants were randomly assigned to a market formed by 4 participants ( 3 participants in Experiment 2). Two participants played the role of the firm, one participant played the role of the consumer, and the remaining participant played the role of the third party on which the negative externality from trading unfair product(s) would be imposed (in Experiment 2, the negative externality was imposed on a charity). After each round, new markets were randomly formed. Rematching to form new markets every round is done within groups of 8 participants (6 participants in Experiment 2). We treat observations from different rematching groups as statistically independent. The role of firms and consumers was randomly alternated. The role of the third party was kept fixed during the 24 rounds of the market game to avoid strategic reciprocal behavior, i.e. colluding on only trading the fair good - which maximizes the group's joint payoffs. Using human consumers on the demand side, instead of a simulated aggregate demand function as is common in oligopoly experiments, allows us to measure the effect of consumer preferences on market behavior.12 Firms and consumers could trade two types of products: an 'unfair' product, which imposes a negative externality to the third party, and a 'fair' product, which has no impact on the income for the third party. Consumers could also choose not to buy any product, in which case the externality to the third party was also avoided. More specifically, consumers and firms, in each round, interact in the following three-stage market game:

1. Firms simultaneously and independently choose the type of product at which they want to offer the product. All product types become common knowledge for the firms.

12 Other oligopoly experiments that have consumer participants, in altogether different settings, are Tyran \& Engelmann (2005), Davis \& Wilson (2008), and Orland \& Selten (2016). 
2. Firms simultaneously and independently choose the price of product at which they want to offer the product. All product types become common knowledge for the firms. Firms can only sell one unit of the good.

3. The consumer observes the offers (price and type of product) and makes a purchasing decision. The consumer can buy one of the products offered or not buy at all.

Our set-up diverges from that in Bartling et al.'s (2015) in three ways. First, we chose a one-shot market structure with alternating roles of consumers and firms instead of a repeated market game with fixed roles. This avoids tacit coordination on prices that could arise in a repeated market environment, so that we can focus on the effect of the opportunity to coordinate regarding the kind of good offered. Role switching also enlarges the pool where consumers and firms are drawn from, which results in a closer approximation of the smooth distribution of consumer types assumed in our theoretical analysis than without role switching. Second, our firms do not simultaneously decide on the kind of good offered and the price. Instead, firms only decide on the price after observing the kind of good offered by the other firm. This sequential set-up follows the way product differentiation is modeled in the industrial-organization literature of semi-collusion that is used to study the policy of allowing coordination on product type. ${ }^{13}$

A third divergence from Bartling et al.'s (2015) experiment is that, for reasons of statistical convenience, we kept the number of participants in markets as low as possible: our markets consist of two firms and one consumer making decisions. While Bartling et al. (2015) studies markets with more firms (five), consumers (four) and third parties (three), competition in our experimental markets is still strong, due to the one-shot nature of our game, head-on price competition between homogenous goods (in the case of symmetric product choices) in the second stage, and alternating roles of consumers and firms. In fact, our market games appear on average to be more competitive than those in Bartling et al. (2015). In our setting, the average price for the fair [unfair] good represents 31.25\% [22\%] of the consumers' value for the good. In contrast, the average price for the fair [unfair] good represents $56.25 \%$ [48.1\%] of the consumers' value for the good in Bartling et al. (2015). Moreover, Bartling et al. (2015) do not find significant changes in social responsible attitudes when increasing seller competition in their experimental markets. In addition, Bartling et al. (2017) find the number of affected third parties had no substantial effect on socially responsible market behavior.

We used the following parameters of the market game: The production costs were $c^{u}=0$ for the unfair good and $c^{f}=15$ for the fair good. The price set was $P=\{0,1,2, \ldots, 100\}$. The consumer's value for buying a good was equal to $v=80$. All participants began a round with a starting capital

\footnotetext{
${ }^{13}$ See Schinkel \& Spiegel (2017) and the references therein.
} 
of 70. The third party's payoff was reduced by $x=70$ if the consumer bought the unfair good and remained unchanged if the consumer did not buy a good or bought the fair good. Hence, the resulting payoffs are:

$$
\begin{gathered}
\Pi^{\text {firm }}=\left\{\begin{array}{cc}
70+p & \text { if the firm sells the unfair good at price } p \\
70+p-c^{f} & \text { if the firm sells the fair good at price } p \\
70 & \text { if the firm does not sell }
\end{array}\right. \\
\Pi^{\text {consumer }}=\left\{\begin{array}{cc}
70+v-p & \text { if the consumer buys a good at price } p \\
70 & \text { if the consumer does not buy }
\end{array}\right. \\
\Pi^{\text {third party }}=\left\{\begin{array}{cc}
70-x & \text { if the consumer buys the unfair good } \\
70 & \text { otherwise }
\end{array}\right.
\end{gathered}
$$

It is readily verified that for the experimental parameters, the parameter space implied by Assumptions A1-A4 is non-empty. For instance, $\bar{\gamma}=50$, and $\bar{\varphi}=30$ satisfy these assumptions for $\alpha \geq 0.8$. The empirical third-party preference distributions displayed in Figure 1 are essentially in this region.

The experimental design contains two treatments that vary in the opportunity for the firms to coordinate on the kind of good sold - reflecting the policy choice to allow or not to allow competitors' sustainability agreements under the antitrust laws. In treatment No CoORDINATION, the participants interact in the market game in full competition, i.e., they cannot collaborate on the kind of good offered. In treatment COORDINATION, participants interact in the coordination mechanism described above, before playing the market game. That is, the firms can reach an agreement regarding the kind of good each will offer in the first stage of the market game on the basis of alternating-offers negotiation. We have restricted the firms to communicate only about the kind of good offered, because free-form communication is known to help subjects to increases prices in the lab (Isaac et al., (1984), Fonseca \& Normann (2012), and Gomez-Martinez et al. (2016)). This setup follows the policy proposal to only allow sustainability agreement: any other exchange of commercially sensitive information remains a per se cartel infringement. Nevertheless, the alternating-offers negotiation gives the firms also opportunity to coordinate on producing the unfair product instead, if this is more profitable. This kind of abuse of the policy, which has been voiced as a concern in more complex practical settings, is not expected to happen according to our theoretical analysis (Schinkel and Treuren, 2021a).

\subsection{Experiment 1: Baseline}

For our baseline Experiment 1, we recruited participants from a mandatory Economics course in the UvA's PPLE (Politics, Psychology, Law and Economics) bachelor program. Of the 136 students who participated in Experiment 1, 72 [64] participants were assigned to the CoORDINATION [No 
COORDINATION] treatment resulting in 432 [384] one-shot games. The participants did not receive a show-up fee. Their earnings ranged from $€ 0$ to $€ 14.90$ with an average of $€ 7.70$.

In the following presentation of our experimental results, by 'the effect of CSR collaboration,' we mean differences observed between the treatments COORDINATION and No COORDINATION. In section 4.2.1, we examine whether CSR collaboration has an impact on aggregate market outcomes. In section 4.2.2, individual behavior for both consumers and firms is analyzed and, in particular, linked with the third-party preferences measured in part 1 of the experiment.

\subsubsection{The Effect of CSR Collaboration on Aggregate Market Outcomes}

We first examine the effects of collaboration possibilities on market outcomes. The second column in Table 3 shows that the fair good is traded in almost $2 / 3$ of the market interactions for both treatments. Between treatments, there are no significant differences in the proportion of fair goods traded ( $\mathrm{p}$-value $=0.820$ ) nor unfair goods traded ( $\mathrm{p}$-value $=0.767$ ). The proportion of transactions rejected by the consumer is not affected by CSR collaboration either (pvalue $=0.851$ ). Finally, the proportion of fair goods offered by the sellers is not affected by CSR collaboration ( $p=1.000)$. Therefore, we can conclude that CSR collaboration does not increase fair trade in the total sample.

Result 1. CSR collaboration does not affect the fraction of fair goods traded.

This finding rejects Hypothesis 1.

Table 3: Type of goods traded, market prices, and offer types in Experiment 1

\begin{tabular}{|c|c|c|c|c|c|c|c|c|c|}
\hline Treatment & $\begin{array}{l}\text { Fraction } \\
\text { fair } \\
\text { goods } \\
\text { traded } \\
\end{array}$ & $\begin{array}{l}\text { Fraction } \\
\text { unfair } \\
\text { goods } \\
\text { traded } \\
\end{array}$ & $\begin{array}{l}\text { No } \\
\text { trade }\end{array}$ & $\begin{array}{l}\text { Fraction } \\
\text { fair goods } \\
\text { offered }\end{array}$ & $\begin{array}{l}\text { Fraction } \\
\text { Fair/Fair } \\
\text { offers }\end{array}$ & $\begin{array}{l}\text { Fraction } \\
\text { Unfair/Unfair } \\
\text { offers }\end{array}$ & $\begin{array}{l}\text { Fraction } \\
\text { Unfair/Fair } \\
\text { offers }\end{array}$ & $\begin{array}{l}\text { Price } \\
\text { fair } \\
\text { good }\end{array}$ & $\begin{array}{l}\text { Price } \\
\text { unfair } \\
\text { good }\end{array}$ \\
\hline $\begin{array}{l}\text { No } \\
\text { COORDINATION }\end{array}$ & $65.36 \%$ & $25.78 \%$ & $8.85 \%$ & $65.23 \%$ & $43.49 \%$ & $13.02 \%$ & $43.49 \%$ & 24.96 & 18.27 \\
\hline COORDINATION & $63.66 \%$ & $28.01 \%$ & $8.33 \%$ & $66.20 \%$ & $54.63 \% * *$ & $22.22 \%{ }^{* *}$ & $23.15 \% * * *$ & 24.19 & 16.45 \\
\hline $\mathbf{N}$ & 816 & 816 & 816 & 1632 & 408 & 408 & 408 & 526 & 220 \\
\hline
\end{tabular}

Notes: ${ }^{*} \mathrm{p}<0.1,{ }^{* *} \mathrm{p}<0.05,{ }^{* * *} \mathrm{p}<0.01$. Significance calculation based on individual level random effects regressions with robust standard errors clustered by subject. Only a dummy variable for the COORDINATION treatment is included as explanatory variable.

However, CSR collaboration does turn out to affect product variety. The number of instances in which both firms offer the fair good increases from $43.49 \%$ to $54.63 \%$ when coordination possibilities are introduced ( $\mathrm{p}$-value=0.050). The fraction of firms coordinating on offering only the unfair good is also increased from $13.02 \%$ to $22.22 \%$ (p-value=0.032). As a consequence, CSR collaboration leads to more symmetric offers faced by consumers: firms tend to coordinate on both offering the same good (fair or unfair), and therefore product variety decreases (p- 
value $=0.000) .{ }^{14}$ Therefore, CSR collaboration has a negative effect on product variety in the full sample.

\section{Result 2. CSR collaboration decreases product variety.}

Hence, we reject Hypothesis 2. The opportunity to make CSR agreements polarizes: more of the same type of good, fair or unfair, is offered when firms are allowed to coordinate. Result 1 is explained by the in- and decreases in fair product offered canceling out on average.

An implication of this result is that, due to the strong increase in symmetric unfair offers, the fraction of cases in which at least one fair good is offered that consumers could accept to be traded decreases from $86.98 \%$ in the No COORDINATION treatment to $77.78 \%$ in the COORDINATION treatment ( $p$-value=0.032). Even though the proportion of offers where the consumers could choose the fair product substantially decrease due to coordination, the share of fair goods traded does not differ significantly in the two treatments (see Result 1). Consumers still pick the same share of fair goods in the COORDINATION treatment.

We find also that CSR collaboration does not affect the market prices for the fair and unfair product. The average price for the fair good is 24.96 in the No COORDINATION treatment and 24.19 in the COORDINATION treatment. These numbers are not significantly different ( $p$-value $=0.401$ ). The same applies for the prices for the unfair good that are, on average, 18.27 in the No COORDINATION treatment and 16.45 in the COORDINATION treatment ( $p$-value=0.374). Since market prices and the share of fair goods traded is not affected by CSR collaboration, consumer surplus and producer surplus are not significantly different across treatments. Consumer surplus, based on the third-party preferences measured in part 1 of the experiment, equals 144.66 [145.38] in the No COORDINATION [COORDINATION] treatment. Firm profits are equal to 75.61 [75.23] in the No COORDINATION [COORDINATION] treatment. Producer surplus, based on third-party preferences, equals 96.32 [95.06] in the No COORDINATION [COORDINATION] treatment.

Result 3. CSR collaboration does not affect prices of fair and unfair goods, producer surplus, or consumer surplus.

We reject hypothesis 3 . Note that these findings are consistent with those above that overall collaboration on the choice of product type does not work to increase trade in more fair products or more product differentiation in the full sample, despite a setting in which it should work

\footnotetext{
${ }^{14}$ Firms are both more likely to make and more likely to accept symmetric offers than asymmetric offers. $67 \%$ of the offers made in the coordination mechanism are symmetric $(46 \%$ fair/fair and $21 \%$ unfair/unfair). Symmetric offers are significantly more likely to be accepted than asymmetric offers (75\% [56\%] of the fair/fair [unfair/unfair] offers are accepted, while only $35 \%$ of the asymmetric offers are accepted).
} 
theoretically. These findings suggest that a broad policy of exempting anticompetitive agreements about collaborative CSR may not be effective in unspecified populations.

The price premium for the fair goods relative to the unfair good indicates that firms and consumers care about the negative externality that an unfair product inflicts on the third party in the lab. The average market price premium for the fair good is 6.69 in the No CoordinATION treatment and 7.74 in the COORDINATION treatment; the difference is not statistically significant $(p=0.701)$. Therefore, consistent with the assumptions underlying our theoretical analysis, consumers are willing to pay more for the fair good than for the unfair good. As the production costs for the fair good are 15 higher than for the unfair good, it turns out that firms are also willing to give up some profits to sell the fair good, in line with our theoretical assumption that at least some of them internalize the negative externality. Indeed, firms and consumers share the additional production costs of the fair good approximately evenly, which is also found to be the case in Bartling et al. (2015).

The above results remain consistent when introducing time trends into the analysis. Figure 2, panel a, shows the evolution of the share of fair goods traded over time for both treatments. This figure suggests that the share of fair goods traded increases over time and that, again, there is no treatment effect, i.e., CSR collaboration does not increase fair trade. This is confirmed in specification (1) in Table 4.

The evolution of offer types by treatment is represented in Figure 2, panels b-d, and estimated in specifications (2), (3), and (4) in Table 4. The proportion of asymmetric offers is constant over time and clearly lower when firms have the opportunity to coordinate. The fraction of symmetric fair offers is slightly increasing over time. The proportion of symmetric unfair offers is decreasing over time for both treatments. There are clearly more symmetric fair offers and symmetric unfair offers in the COORDINATION treatment than in the No COORDINATION treatment. We conclude again that when firms can coordinate on the type of goods sold, they tend to agree on offering the same good (fair or unfair). 
Figure 2: Evolution of the share of fair goods traded, offers and market prices in Experiment 1
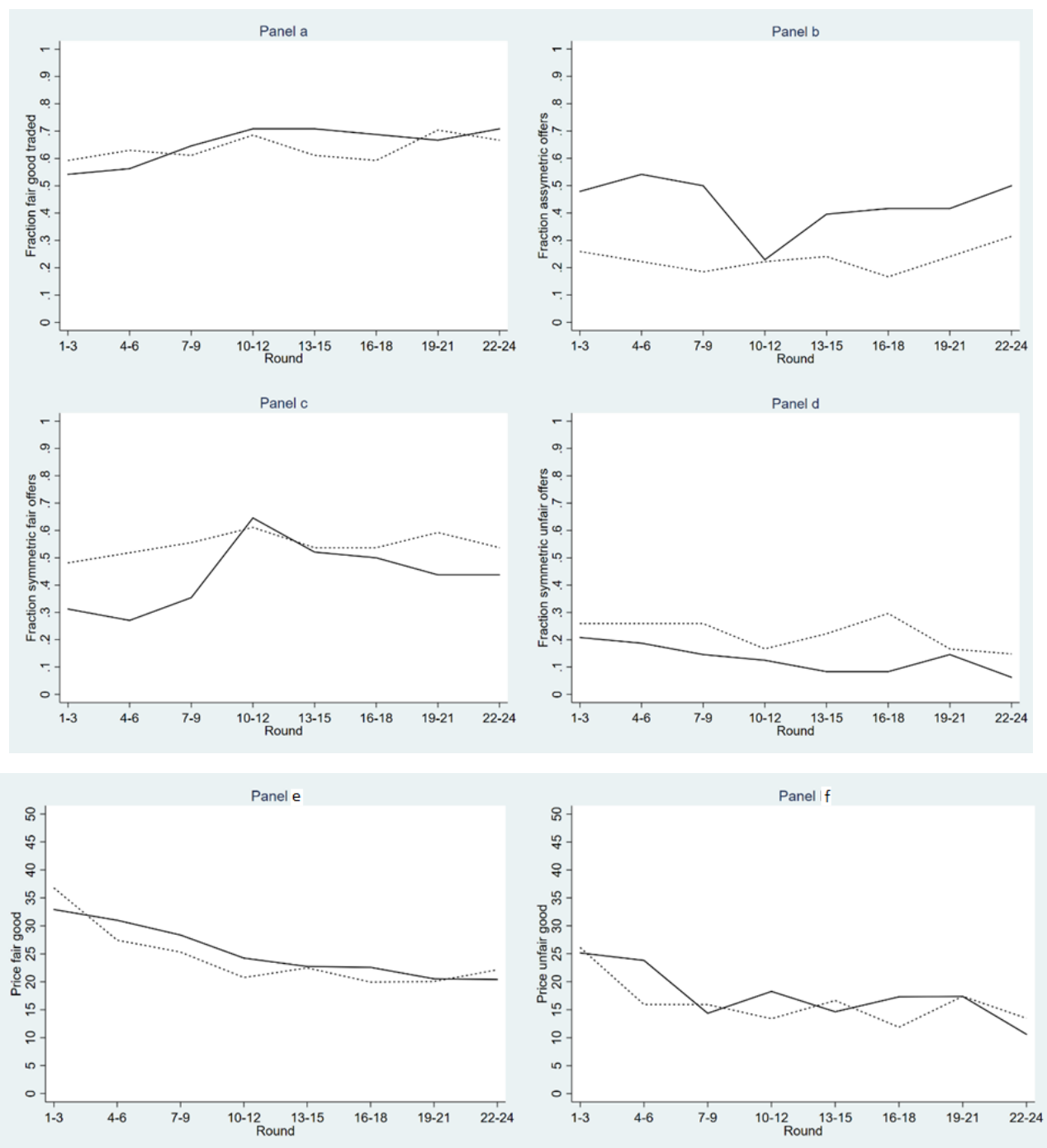

Figure 2, panels e-f, show the evolution of average transaction prices for fair and unfair goods in both treatments. It highlights a clear downward pressure on prices, mainly in the first rounds. All in all, we clearly observe no treatment effect in the average market price for either type of good. Introducing coordination possibilities on the type of goods offered by firms does not affect average market prices for fair and unfair goods. This result is confirmed by specifications (5) and (6) in Table 4. 
Table 4: Random effects regressions of type of goods traded, type of goods offered, and market prices in Experiment 1

\begin{tabular}{|c|c|c|c|c|c|c|}
\hline & $\begin{array}{c}\text { Fair good } \\
\text { traded } \\
(1) \\
\text { Logit }\end{array}$ & $\begin{array}{c}\text { Asymmetric } \\
\text { offer } \\
(2) \\
\text { Logit }\end{array}$ & $\begin{array}{c}\text { Fair/Fair } \\
\text { offer } \\
(3) \\
\text { Logit }\end{array}$ & $\begin{array}{l}\text { Unfair/Unfair } \\
\text { offer } \\
\text { (4) } \\
\text { Logit }\end{array}$ & $\begin{array}{l}\text { Price fair } \\
\text { good } \\
\text { (5) }\end{array}$ & $\begin{array}{l}\text { Price unfair } \\
\text { good } \\
(6)\end{array}$ \\
\hline Intercept & $\begin{array}{l}0.3545 \\
(0.2623)\end{array}$ & $\begin{array}{l}-0.2787 \\
(0.2092)\end{array}$ & $\begin{array}{l}-0.6579 * * * \\
(0.2486)\end{array}$ & $\begin{array}{l}-1.9916^{* * *} \\
(0.3657)\end{array}$ & $\begin{array}{l}32.6931^{* * *} \\
(1.3659)\end{array}$ & $\begin{array}{l}24.2386^{* * *} \\
(2.2685)\end{array}$ \\
\hline COORDINATION & $\begin{array}{l}-0.0649 \\
(0.2807)\end{array}$ & $\begin{array}{l}-0.9910^{* * *} \\
(0.2007)\end{array}$ & $\begin{array}{l}0.5442^{* *} \\
(0.2832)\end{array}$ & $\begin{array}{l}0.7812^{* *} \\
(0.3942)\end{array}$ & $\begin{array}{l}-1.3108 \\
(1.2446)\end{array}$ & $\begin{array}{l}-1.5852 \\
(2.1460)\end{array}$ \\
\hline Period & $\begin{array}{l}0.0328 * * \\
(0.0145) \\
\end{array}$ & $\begin{array}{l}-0.0003 \\
(0.0119)\end{array}$ & $\begin{array}{l}0.0263^{* *} \\
(0.0112) \\
\end{array}$ & $\begin{array}{l}-0.0451^{* * *} \\
(0.0174)\end{array}$ & $\begin{array}{l}-0.5885^{* * *} \\
(0.0709)\end{array}$ & $\begin{array}{l}-0.4965^{* *} \\
(0.1300)\end{array}$ \\
\hline $\mathrm{N}$ & 816 & 408 & 408 & 408 & 526 & 220 \\
\hline
\end{tabular}

These results are initial indication that indeed fair trade depends mainly on consumers attitudes toward the externality. In the following subsection, we zoom further into the question which firm types tend to offer more or less product variety when matched to one another to shed light on how the constitution of the subject pool affects these general findings.

\subsubsection{Firms' and Consumers' Individual Behavior}

In this subsection we turn attention to the individual behavior of consumers and firms. In particular, we examine the relation between the third-party preferences measured in part 1 of the experiment and observed market behavior. To check the accuracy of the way we measure $\gamma$ in part 1, we first examine to what extent participants' choices in the role of consumer are consistent with their third-party preferences measured in part 1 . As the choice between two fair goods is unaffected by a consumer's third-party preference, ${ }^{15}$ we restrict attention to instances in which consumers are offered both types of good or only unfair goods. Excluding all participants who did not exhibit consistent third-party preferences (6.7\%) in part 1 of the experiment, leaves us with 386 observations.

If both the fair good and the unfair good are offered, the consumer buying the [un]fair good is consistent with third-party preferences if, and only if, $\gamma \geq p_{f}-p_{u}\left[\gamma \leq p_{f}-p_{u}\right]$. If both firms offer the unfair good, consumers can only avoid the externality if they decide not to buy any of the goods. Not buying would be consistent with their third-party preferences if, and only if, $\gamma \geq$ $80-p_{\min }$, where $p_{\min }$ is the lower price among the two unfair goods offered.

\footnotetext{
${ }^{15}$ In the case of two fair goods offered, provided that one of the prices is lower than 80 , the consumer should choose the least expensive product regardless of her third-party preferences.
} 
Table 5 reports the frequency of all combinations of predicted and actual decisions made by consumers in Experiment 1. To obtain a conservative prediction of a participant's socially responsible market decision, we assume that an individual participant's $\gamma$ is the minimum value in the interval in which $\gamma$ lays according to the choices made in part 1 of the experiment. Thirdparty preferences revealed in part 1 of the experiment predict a share of $46.63 \%$ of social responsible market decisions (consumers buying the fair good in $45.85 \%$ of the cases and rejecting both offers in $0.77 \%$ of the cases).

The experiment confirms this prediction exactly: Consumers avoided the externality in $46.63 \%$ of the market interactions where consumers could choose whether to avoid the harm to the third party (in $36.27 \%$ of the cases, they purchased the fair good and in $10.36 \%$ of the cases the consumer rejected both offers). The predicted and empirical shares are not significantly different (Wilcoxon signed-rank test $\mathrm{p}=1.000$ ). Consumers behaved in line with their third-party preferences in the vast majority of the cases (79.27\%). In $10.36 \%$ of the cases, market decisions were not socially responsible in contrast with the prediction based on their third-party preferences. In the remaining $10.36 \%$ of the cases, consumer decisions were socially responsible when third-party preferences did not predict such behavior. Therefore, we do not observe systematic deviation towards or away from 'socially responsible' market behavior. We conclude that the measure for $\gamma$ in part 1 of Experiment 1 is accurate.

Table 5: Frequencies of all combinations of predicted and actual consumer choices

\begin{tabular}{ll|lll|l}
\hline & \multicolumn{5}{c}{ Actual choice } \\
& & Fair good & Unfair good & No good & N \\
\cline { 2 - 6 } & \multirow{2}{*}{ Fair good } & 129 & $\mathbf{3 8}$ & 10 & 177 \\
& & $(33.42 \%)$ & $(\mathbf{9 . 8 4 \% )}$ & $(2.59 \%)$ & $(45.85 \%)$ \\
$\begin{array}{l}\text { Predicted } \\
\text { choice }\end{array}$ & \multirow{2}{*}{ Unfair good } & $\underline{11}$ & 166 & $\underline{29}$ & 206 \\
& \multirow{2}{*}{ No good } & - & $(43.01 \%)$ & $\underline{(7.51 \%)}$ & $(53.37 \%)$ \\
& $\mathrm{N}$ & 140 & $\mathbf{2}$ & 1 & 3 \\
& & $(36.27 \%)$ & $(53.37 \%)$ & $(10.36 \%)$ & $(0.77 \%)$ \\
\hline
\end{tabular}

Notes: The predicted choice is based on the lower bound of the third-party preference measured in part 1. Underlined [bold] entries correspond to observations where participant decisions were [not] socially responsible in contrast with the predicted choice.

Next, we study the determinants of consumers' behavior. Table 6 displays the results for the behavior of the consumers in our experimental markets. Specification (1) models the individual decisions about which good to buy (if any). The dependent variable is a dummy taking value 1 if and only if the consumer decides to buy the fair good or not to buy at all. Both decisions imply that the third party does not suffer the negative externality. The share of transactions where consumers decide to avoid the externality is stable over time. In addition, the more participants care about the third party the more likely they are to avoid the externality of buying the fair good or not buying at all. 
Result 4. In the role of consumer, the more a participant cares about the third party, the more likely she is to avoid the externality either by buying the fair good if one is offered or by not buying at all.

We conclude that Hypothesis 4 can be confirmed.

Table 6: Consumer behavior in Experiment 1

\begin{tabular}{|c|c|c|}
\hline & $\begin{array}{c}\text { Avoiding the } \\
\text { externality } \\
\text { (1) } \\
\text { Logit }\end{array}$ & $\begin{array}{c}\text { Fair good } \\
\text { purchased } \\
\text { (2) } \\
\text { Logit }\end{array}$ \\
\hline Intercept & $\begin{array}{c}0.1818 \\
(0.3817)\end{array}$ & $\begin{array}{c}1.9510^{*} \\
(1.0820)\end{array}$ \\
\hline Period & $\begin{array}{c}0.0252 \\
(0.0165)\end{array}$ & $\begin{array}{c}-0.0532 \\
(0.0426)\end{array}$ \\
\hline 3rdPartyPref & $\begin{array}{c}0.0341^{* * *} \\
(0.0094)\end{array}$ & $\begin{array}{c}0.0798^{* * *} \\
(0.0287)\end{array}$ \\
\hline COORDINATION & $\begin{array}{c}-0.2598 \\
(0.3764)\end{array}$ & $\begin{array}{c}-0.6958 \\
(0.8415)\end{array}$ \\
\hline PricediffFU & - & $\begin{array}{c}-0.2366 * * * \\
(0.0687)\end{array}$ \\
\hline $\mathrm{N}$ & 745 & 242 \\
\hline
\end{tabular}

Notes: The dependent variable in (1) takes value 1 if the fair good or no good is bought. Specification (2) restricts the analysis to observations where the consumer receives offers for both types of good. The dependent variable in (2) takes value 1 if the fair good is bought and 0 otherwise. PricediffFU is the difference in prices between the fair and unfair good when both goods are offered. Period takes values from 1 to 24. COORDINATION takes value 1 for the COORDINATION treatment. Observations where participants revealed inconsistent third-party preferences are excluded. The models allow for individual level random effects. Robust standard errors in parentheses (clustered by subject). ${ }^{*} p<0.1,{ }^{* *} p<0.05,{ }^{* * *} p<0.01$.

Moreover, CSR collaboration does not affect the probability of a consumer avoiding the negative externality - even though she faces fewer cases where at least one of the offers is a fair good when CSR coordination. Specification (2) in Table 6 restricts the analysis to observations where the consumer receives offers for both types of good. The dependent variable here takes value 1 if the consumer buys the fair good and 0 if she buys the unfair good. Consistently with (1), there is a positive effect of 3rdPartyPref on the choice of avoiding the externality. Again, there is no treatment effect on the type of good purchased. In addition, an increase in the price difference between the fair and the unfair good decreases the probability of buying the fair good.

Next, we study the determinants of firms' behavior in our experimental markets. Table 7 contains regressions explaining firms' behavior. For each participant, we approximate $\varphi_{i}$ using the variable 3rdPartyPref, which is the midpoint of the interval of $\gamma^{\prime}$ s, consistent with the decision in Table 2 where the participant switches from option A to option B. ${ }^{16}$ Notice that we implicitly assume that the extent to which participants care about the third party is independent of them playing the role of firm or the role of consumer. All models include the period and 3rdPartyPref as explanatory variables. Specification (1) models the individual firms' decisions of which type of

\footnotetext{
${ }^{16}$ When a participant always chooses option A we just know that $\gamma \geq 43.75$. If this is the case we defined $3 r d P a r t y P r e f=43.75$. This means this participant is willing to give up some payoffs if and only if her payoffs are at least as high as the receiver's payoffs in part 1 of the experiment.
} 
good to offer using data from both treatments. The results indicate that the greater participants' 3rdPartyPref, the more likely they are to offer the fair good when assuming the role of a firm.

Result 5. When acting as a firm, the more a participant cares about the third party the more likely she is to offer the fair good.

This confirms Hypothesis 5.

Table 7: Firms' behavior in Experiment 1

\begin{tabular}{|c|c|c|c|c|c|}
\hline & $\begin{array}{c}\text { Fair good } \\
\text { offered } \\
(1) \\
\text { Logit } \\
\end{array}$ & $\begin{array}{l}\text { Fair good } \\
\text { offered } \\
(2) \\
\text { Logit }\end{array}$ & $\begin{array}{c}\text { Unfair/fair } \\
\text { offer } \\
(3) \\
\text { Logit }\end{array}$ & $\begin{array}{c}\text { Fair/Fair } \\
\text { offer } \\
(4) \\
\text { Logit }\end{array}$ & $\begin{array}{c}\text { Unfair/Unfair } \\
\text { offer } \\
\text { (5) } \\
\text { Logit }\end{array}$ \\
\hline Intercept & $\begin{array}{l}-0.3702 \\
(0.3975)\end{array}$ & $\begin{array}{l}-1.0475 \\
(0.7157)\end{array}$ & $\begin{array}{l}-0.6442 \\
(0.5606)\end{array}$ & $\begin{array}{c}0.5728 \\
(0.4603)\end{array}$ & $\begin{array}{c}-1.7054 * * * \\
(0.5564)\end{array}$ \\
\hline Period & $\begin{array}{l}0.0283^{* *} \\
(0.0214)\end{array}$ & $\begin{array}{c}0.0179 \\
(0.0172)\end{array}$ & $\begin{array}{l}0.0539 * \\
(0.0314)\end{array}$ & $\begin{array}{c}0.0322 \\
(0.0291)\end{array}$ & $\begin{array}{c}-0.0496^{* * *} \\
(0.0715)\end{array}$ \\
\hline 3rdPartyPref & $\begin{array}{c}0.0418^{* * *} \\
(0.0122)\end{array}$ & $\begin{array}{c}0.0321 \\
(0.0205)\end{array}$ & - & - & $\begin{array}{l}-0.0039 \\
(0.0138)\end{array}$ \\
\hline 3rdPartyPrefOther & - & $\begin{array}{c}0.0117 \\
(0.0078)\end{array}$ & - & - & $\begin{array}{l}-0.0070 \\
(0.0077)\end{array}$ \\
\hline COORDINATION & $\begin{array}{l}-0.1798 \\
(0.4285)\end{array}$ & - & $\begin{array}{c}1.0786^{* * *} \\
(0.3727)\end{array}$ & $\begin{array}{c}0.2866 \\
(0.3727)\end{array}$ & $\begin{array}{c}0.6927 \\
(0.4796)\end{array}$ \\
\hline Agreement & - & $\begin{array}{c}0.8071^{* * *} \\
(0.3102)\end{array}$ & - & - & - \\
\hline $\mathrm{N}$ & 1487 & 622 & 48 & 119 & 513 \\
\hline \multicolumn{6}{|c|}{$\begin{array}{l}\text { Notes: The dependent variable in (1) and (2) takes value } 1 \text { if the fair good is offered. Period takes values from } 1 \text { to } 24 \text {. Agreement in ( } \\
\text { takes value } 1 \text { if firms reach an agreement in the COORDINATION treatment. COORDINATION takes value } 1 \text { for the COORDINATION treatment. ( } \\
\text { is restricted for observations where both firms in the same market are unconditionally selfish i.e. 3rdPartyPref }=2.1875 \text {. Specification } \\
\text { is restricted for observations where both firms in the same market are unconditionally altruistic i.e. SrdPartyPref=43.75. Specificati } \\
\text { (5) is restricted to the remaining observations. Observations where participants revealed inconsistent third-party preferences a } \\
\text { excluded. The models allow for individual level random effects. Robust standard errors in parentheses (clustered by subject). * }{ }^{*}<0 \\
*{ }^{* *}<0.05,{ }^{* * *} p<0.01 \text {. }\end{array}$} \\
\hline
\end{tabular}

Moreover, CSR collaboration does not affect the probability of offering the fair good. The likelihood of firms offering the fair good is increasing in time. Specification (2) studies the effect that firms reaching an agreement has on the likelihood of offering a fair good in the CoORDINATION treatment. Since reaching an agreement depends on both firms' preference, we include an additional variable that measures the third party preference of the other firm matched in the same market, 3rdPartyPrefOther. We find that it is more likely that an individual firm offers a fair good when an agreement is reached, without that effect increasing the average supply of fair goods (as shown in previous section). This suggests a selection effect, in the sense that firms intending to offer a fair good are more inclined to reach an agreement.

We also find support for Hypothesis 6. In specification (3) in Table 7, we restrict the analysis to the cases where both firms in the same market are unconditionally selfish, i.e., they always choose 
option B in Table 2 in part 1 of the experiment. We find that such type- 0 firms are more likely to make an asymmetric offer when coordination is introduced.

Result 6. CSR collaboration induces firm that do not internalize the externality to differentiate their products.

This finding confirms the insight from theory that the ability to make CSR agreements is a profitable proposition only for firms that both offer the unfair product in competition - due to their low intrinsic appreciation of avoiding causing externalities - who use it to soften their price competition by differentiating their products: to agree that one of them switches to offering the fair good. The subsample of unconditionally selfish participants turned out to be too small, however, for this predicted effect to appear in the entire sample as well.

Specification (4) investigates the hypothesis that CSR collaboration does not facilitate fair production among firms with high third-party preferences concerning the externality. In particular, specification (4) restricts the analysis for the case where both firms in the same market are unconditionally altruistic ( $3 r d P a r t y P r e f=43.75)$. We do not find evidence that the opportunity to coordinate helps firms with strong third-party preferences to coordinate more frequently on symmetric fair production.

Result 7. CSR collaboration does not helps firm with high third party preferences to coordinate on both offering the fair good.

This confirms Hypothesis 7.

Finally, specification (5) considers the remaining observations, where both firms are not unconditionally selfish or altruistic. The results show that this subsample of firms are more inclined to both offer the unfair good. Although the effect is not statistically significant, the observation contributes to understanding the overall conclusion that CSR collaboration has a negative impact on product variety - i.e. see Result 2. Essentially, the overall effects of CSR collaboration are negligible because positive effect on the fraction of fair goods offered by selfish firms is overshadowed by the negative, but statistically insignificant effect in the large group of subjects with medium social preferences who offer more unfair products. These findings suggest that exemptions of collaborative CSR agreements from the cartel prohibition should only be given in well-specified cases and not be generally available. 


\subsection{Experiment 2: Carbon Emission Compensation Certificates}

In the baseline experiment (Experiment 1), the negative externality was imposed on a single third party present in the lab. In many market settings, externalities are more abstract and impersonal, in the sense that they have a small impact on a large number of people. This is the case, for example, of carbon emissions. We ran Experiment 2 to check the robustness of the findings in the previous subsection, with a different subject pool, in a setting where the externality was imposed on a charity. In part 2 of Experiment 2, we informed the participants that when the fair good (or no good) was traded the experimenter would buy $€ 7$ worth of carbon emission compensation certificates from Carbonfund.org, "an organization that allows individuals to offset their carbon footprint, which includes the emissions from their homes, cars, and air travel". ${ }^{17}$ The instructions specified that 1 euro donated "allows offsetting about $110 \mathrm{~kg}$ of CO2." If the unfair good was traded, we would not buy any carbon emission compensation certificates. Similarly, in part 1, the payoffs for the receiver would be donated to Carbonfund.org. To enhance the credibility this commitment, we announced in the instructions that the total amount raised at the end of each session would be donated publicly.

A total of 96 participants were recruited from the general student population of the University of Amsterdam for Experiment 2. The participants were equally split over the COORDINATION and No COORDINATION treatments resulting in 384 one-shot games per treatment. The average earnings were $€ 16.98$, including a show-up fee of $€ 7.50$, with a minimum of $€ 14.50$ and a maximum of $€ 22.40$. We donated $€ 84$ to CarbonFund.org.

In this section we highlight differences in findings between Experiments 1 and 2 by only indicating where they differ in the numbered result summaries; we add an apostrophe to the corresponding result. Before we discuss the results, we wish to highlight a marked difference between the two experiments (and Experiment 3). Figure 1 clearly shows that third-party preferences are weaker in Experiment 2 than in Experiments 1 and 3. In fact, the empirical distribution of third-party preferences in both Experiments 1 and 3 first-order stochastically dominates the one in Experiment 2. The difference is statistically significant (two-sample combined Kolmogorov-Smirnov test, $\mathrm{p}=0.023) .{ }^{18}$ This is in line with our expectation that in this setting with carbon emission compensation, participants would be less concerned about the

\footnotetext{
${ }^{17}$ Other experimental papers linking 'fair trade' to donations to a charity include Rode et al. (2008), Kirchler et al. (2016), Soetevent et al. (2016), and Sutter et al. (2020).

${ }^{18}$ In Experiment 2, consumers behaved in line with their third-party preferences in $89.54 \%$ of the selected observations. We observe a slight bias towards fewer socially responsible market decisions: consumers avoided the externality in $20.93 \%$ of the relevant market interactions, which is significantly less than the predicted $24.87 \%$ (Wilcoxon signed-rank test, $\mathrm{p}=0.009$ ).
} 
externality caused by offering and accepting the unfair product, because the harm would not be personal and therefore more distant than in Experiment 1.

As Experiments 1 and 2 differ in three dimensions (the nature of the externality, the distribution of third-party preferences, and the subject pool), we cannot attribute observed differences to one or the other change. As it turns out, the two experiments qualitatively yield the same main results, adding to the robustness of the findings in Experiment 1 to a setting where participants care less about the externality. In the following, we highlight the differences.

\subsubsection{The Effect of CSR collaboration on Aggregate Market Outcomes}

As in Experiment 1, the introduction of coordination possibilities does not significantly affect the share of fair goods traded. Similarly, there are no significant differences in the share of unfair goods traded nor in the likelihood that the transaction occurs. On the other hand, the fraction of fair goods traded is significantly lower than in Experiment 1: the fair good was traded in about $1 / 3$ of the cases, while this happened in almost $2 / 3$ of the cases in Experiment $1 .{ }^{19}$ Like in Experiment 1, participants tend to coordinate more on symmetric offers if they have the opportunity to coordinate, albeit less often on the fair products. ${ }^{20}$

Table 8: Type of goods traded, market prices, and offer types in Experiment 2

\begin{tabular}{|c|c|c|c|c|c|c|c|c|c|}
\hline Treatment & $\begin{array}{l}\text { Fraction } \\
\text { fair } \\
\text { goods } \\
\text { traded } \\
\end{array}$ & $\begin{array}{l}\text { Fraction } \\
\text { unfair } \\
\text { goods } \\
\text { traded } \\
\end{array}$ & $\begin{array}{l}\text { No } \\
\text { trade }\end{array}$ & $\begin{array}{l}\text { Fraction } \\
\text { fair goods } \\
\text { offered }\end{array}$ & $\begin{array}{l}\text { Fraction } \\
\text { Fair/Fair } \\
\text { offers }\end{array}$ & $\begin{array}{l}\text { Fraction } \\
\text { Unfair/Unfair } \\
\text { offers }\end{array}$ & $\begin{array}{l}\text { Fraction } \\
\text { Unfair/Fair } \\
\text { offers }\end{array}$ & $\begin{array}{l}\text { Price } \\
\text { fair } \\
\text { good }\end{array}$ & $\begin{array}{l}\text { Price } \\
\text { unfair } \\
\text { good }\end{array}$ \\
\hline $\begin{array}{l}\text { No } \\
\text { COORDINATION }\end{array}$ & $34.90 \%$ & $61.96 \%$ & $3.14 \%$ & $35.94 \%$ & $17.71 \%$ & $45.83 \%$ & $36.46 \%$ & 34.11 & 19.44 \\
\hline COORDINATION & $35.42 \%$ & $63.54 \%$ & $1.04 \%$ & $35.55 \%$ & $23.18 \%$ & $52.08 \%$ & $24.74 \% * * *$ & $27.51^{* * *}$ & 19.55 \\
\hline $\mathbf{N}$ & 768 & 768 & 768 & 1536 & 384 & 384 & 384 & 270 & 482 \\
\hline
\end{tabular}

Notes: ${ }^{*} \mathrm{p}<0.1,{ }^{* *} \mathrm{p}<0.05,{ }^{* * *} \mathrm{p}<0.01$. Significance calculation based on individual level random effects regressions with robust standard errors clustered by subject. Only a dummy variable for the COORDINATION treatment is included as explanatory variable.

Different from Experiment 1, in Experiment 2 the price for the fair good decreases when CSR coordination is introduced as a possibility. When firms can coordinate on the type of good that they offer, market price for the fair good is, on average, 6.6 units lower. This pattern is clearly seen in the econometric analysis using model (5) reported in Table 9. As in Experiment 1, the price for the unfair good is not significantly different when coordination possibilities are

\footnotetext{
${ }^{19}$ Bartling et al. (2017) find that the share of fair products traded is not significantly different when the harm is diffused over several third parties, compared to when it is concentrated in one person. The reason for our finding of a lower share of fair products may be that in Experiment 2 the harm is even more diffused, and/or because the third party is not present in the lab.

${ }^{20}$ The fraction of symmetric fair or symmetric unfair offers individually are not significantly different across treatments.
} 
introduced. However, on the aggregate, we do not find that the firms' ability to coordinate has a significant impact on consumer surplus or producer surplus. Consumer surplus, based on the third-party preferences measured in part 1 of the experiment, equals 133.52 [133.49] in the No COORDination [COORDinATION] treatment. Firm profits are equal to 79.36 [78.43] in the No COORDINATION [COORDINATION] treatment. Producer surplus, based on third-party preferences, equals 88.64 [85.72] in the No COORDINATION [COORDINATION] treatment. The result on prices of the fair good is different from Result 3 of Experiment 1:

Result 3'. CSR collaboration yields a lower price for the fair good. It does not affect the price of the unfair good, consumer surplus or producer surplus.

Table 9: Random effects regressions of type of goods traded, type of goods offered, and market prices in Experiment 2

\begin{tabular}{|c|c|c|c|c|c|c|}
\hline & $\begin{array}{c}\text { Fair good } \\
\text { traded } \\
(1) \\
\text { Logit }\end{array}$ & $\begin{array}{c}\text { Asymmetric } \\
\text { offer } \\
(2) \\
\text { Logit }\end{array}$ & $\begin{array}{c}\text { Fair/Fair } \\
\text { offer } \\
\text { (3) } \\
\text { Logit }\end{array}$ & $\begin{array}{l}\text { Unfair/Unfair } \\
\text { offer } \\
\text { (4) } \\
\text { Logit }\end{array}$ & $\begin{array}{l}\text { Price fair } \\
\text { good } \\
\text { (5) }\end{array}$ & $\begin{array}{l}\text { Price unfair } \\
\text { good } \\
(6)\end{array}$ \\
\hline Intercept & $\begin{array}{l}-0.9221^{* * *} \\
(0.3268)\end{array}$ & $\begin{array}{l}-0.6248^{* * *} \\
(0.2551)\end{array}$ & $\begin{array}{l}-2.3043 \\
(0.4206)\end{array}$ & $\begin{array}{l}-0.1552 \\
(0.2758)\end{array}$ & $\begin{array}{l}44.3812^{* * *} \\
(1.5713)\end{array}$ & $\begin{array}{l}27.7443^{* * *} \\
(1.7091)\end{array}$ \\
\hline COORDINATION & $\begin{array}{l}0.1229 \\
(0.3252)\end{array}$ & $\begin{array}{l}-0.6394^{* * *} \\
(0.0147)\end{array}$ & $\begin{array}{l}0.6150 \\
(0.3941)\end{array}$ & $\begin{array}{l}0.3309 \\
(0.3069)\end{array}$ & $\begin{array}{c}-5.4594^{* * *} \\
(1.1135)\end{array}$ & $\begin{array}{l}-0.6179 \\
(1.6692)\end{array}$ \\
\hline Period & $\begin{array}{l}0.0034 \\
(0.0137) \\
\end{array}$ & $\begin{array}{l}-0.0013 \\
(0.0147)\end{array}$ & $\begin{array}{l}0.00718 \\
(0.0185) \\
\end{array}$ & $\begin{array}{l}-0.0041 \\
(0.2758) \\
\end{array}$ & $\begin{array}{l}-0.8823^{* * *} \\
(0.0829)\end{array}$ & $\begin{array}{l}-0.6186^{* * *} \\
(0.0551)\end{array}$ \\
\hline $\mathrm{N}$ & 768 & 384 & 384 & 384 & 270 & 482 \\
\hline
\end{tabular}

\subsubsection{Firms' and Consumers' Individual Behavior}

Table 10 contains the results for consumer behavior in Experiment 2. Consistently with Experiment 1, the more participants care about the third party, the more likely they are to avoid the externality when acting as consumers. Again, the ability of firms to coordinate does not affect the probability that the consumer will avoid the externality. Table 11 presents regressions explaining firms' behavior in Experiment 2. Consistently with Experiment 1, the stronger participants' third-party preferences, the more likely they are to offer the fair good. Like in Experiment 1, we find no significant treatment effect on the likelihood of offering unfair or fair symmetric offers. The only main difference from Experiment 1 is that the likelihood that unconditionally selfish firms offer asymmetric offers does not increase when firms are able to coordinate. One possible explanation for this may be that the weaker felt externality makes that the firms perceive to profit less from offering a fair product in product differentiation. We emphasize the difference with Result 6 of Experiment 1 as: 
Result 6'. CSR collaboration does not induce firm that do not internalize the externality to differentiate their products.

Table 10: Consumer behavior in Experiment 2

\begin{tabular}{|c|c|c|}
\hline & $\begin{array}{l}\text { Avoiding the } \\
\text { externality } \\
\text { (1) } \\
\text { Logit }\end{array}$ & $\begin{array}{c}\text { Fair good } \\
\text { purchased } \\
\text { (2) } \\
\text { Logit }\end{array}$ \\
\hline Intercept & $\begin{array}{c}-1.7033^{* * *} \\
(0.4120)\end{array}$ & $\begin{array}{c}0.7904 \\
(1.0424)\end{array}$ \\
\hline Period & $\begin{array}{c}0.0031 \\
(0.0143)\end{array}$ & $\begin{array}{c}-0.0328 \\
(0.0460)\end{array}$ \\
\hline 3rdPartyPref & $\begin{array}{c}0.0475^{* * * *} \\
(0.0138)\end{array}$ & $\begin{array}{l}0.1542^{* *} \\
(0.0661)\end{array}$ \\
\hline COORDINATION & $\begin{array}{c}0.1012 \\
(0.3456)\end{array}$ & $\begin{array}{l}-0.6818 \\
(0.8415)\end{array}$ \\
\hline PricediffFU & - & $\begin{array}{c}-0.3438^{* * *} \\
(0.0958) \\
\end{array}$ \\
\hline $\mathrm{N}$ & 726 & 225 \\
\hline
\end{tabular}

Notes: The dependent variable in (1) takes value 1 if the fair good or no good is bought. Specification (2) restricts the analysis to observations where the consumer receives offers for both types of good. The dependent variable in (2) takes value 1 if the fair good is bought and 0 otherwise. PricediffFU is the difference in prices between the fair and unfair good when both goods are offered. Period takes values from 1 to 24. COORDINATION takes value 1 for the COORDINATION treatment. Observations where participants revealed inconsistent third-party preferences are excluded. The models allow for individual level random effects. Robust standard errors in parentheses (clustered by subject). ${ }^{*} p<0.1,{ }^{* *} p<0.05,{ }^{* *} p<0.01$.

Table 11: Firms' behavior in Experiment 2

\begin{tabular}{|c|c|c|c|c|c|}
\hline & $\begin{array}{l}\text { Fair good } \\
\text { offered } \\
(1) \\
\text { Logit } \\
\end{array}$ & $\begin{array}{l}\text { Fair good } \\
\text { offered } \\
(2) \\
\text { Logit } \\
\end{array}$ & $\begin{array}{c}\text { Unfair/fair } \\
\text { offer } \\
(3) \\
\text { Logit }\end{array}$ & $\begin{array}{c}\text { Fair/Fair } \\
\text { offer } \\
(4) \\
\text { Logit }\end{array}$ & $\begin{array}{c}\text { Unfair/Unfair } \\
\text { offer } \\
\text { (5) } \\
\text { Logit }\end{array}$ \\
\hline Intercept & $\begin{array}{c}-3.4699 * * * \\
(0.5702)\end{array}$ & $\begin{array}{c}-3.7728 * * * \\
(0.7914)\end{array}$ & $\begin{array}{l}-5.7960 * \\
(3.2755)\end{array}$ & $\begin{array}{c}1.6408 \\
(1.2259)\end{array}$ & $\begin{array}{c}1.7709 * * * \\
(0.0218)\end{array}$ \\
\hline Period & $\begin{array}{c}0.0131 \\
(0.0158)\end{array}$ & $\begin{array}{l}0.0421^{* *} \\
(0.0192)\end{array}$ & $\begin{array}{c}0.2165 \\
(0.1389)\end{array}$ & $\begin{array}{c}-0.1535^{* * *} \\
(0.0520)\end{array}$ & $\begin{array}{l}-0.0062 \\
(0.0128)\end{array}$ \\
\hline 3rdPartyPref & $\begin{array}{c}0.1094^{* * *} \\
(0.0214)\end{array}$ & $\begin{array}{c}0.0955^{* * *} \\
(0.0299)\end{array}$ & - & - & $\begin{array}{c}-0.0597^{* * *} \\
(0.0164)\end{array}$ \\
\hline 3rdPartyPrefOther & - & $\begin{array}{l}0.0238^{* *} \\
(0.0104)\end{array}$ & - & - & $\begin{array}{c}-0.0454 * * * \\
(0.0101)\end{array}$ \\
\hline Coordination & $\begin{array}{c}0.5115 \\
(0.5163)\end{array}$ & - & $\begin{array}{c}-0.4129 \\
(1.1996)\end{array}$ & $\begin{array}{c}0.8934 \\
(1.4055)\end{array}$ & $\begin{array}{c}0.0173 \\
(0.3361)\end{array}$ \\
\hline Agreement & - & $\begin{array}{c}0.3899 \\
(0.5509)\end{array}$ & - & - & - \\
\hline $\mathrm{N}$ & 1458 & 672 & 27 & 24 & 639 \\
\hline
\end{tabular}

Notes: The dependent variable in (1) and (2) takes value 1 if the fair good is offered. Period takes values from 1 to 24. Agreement in (2) takes value 1 if firms reach an agreement in the COORDINATION treatment. COORDINATION takes value 1 for the COORDINATION treatment. (3) is restricted for observations where both firms in the same market are unconditionally selfish i.e. 3rdPartyPref=2.1875. Specification (4) is restricted for observations where both firms in the same market are unconditionally altruistic i.e. 3rdPartyPref=43.75. Specification (5) is restricted to the remaining observations. Observations where participants revealed inconsistent third-party preferences are excluded. The models allow for individual level random effects. Robust standard errors in parentheses (clustered by subject). * $p<0.1$, ${ }^{* *} p<0.05,{ }^{* * *} p<0.01$. 


\subsection{Experiment 3: Alternative Coordination Mechanism}

The coordination mechanism in experiments 1 and 2, in which the two participants playing a firm could use alternating-offers negotiation to reach an agreement on the kind of good each offered, is more complex than the one featuring in the theory, in which the firms make any joint profit maximizing product choices. In Experiment 3 we tried to stay closer to the policy proposal by, in the otherwise same framework as in Experiment 1, allowing the firms to coordinate only on both offering the fair good, i.e. increase their CSR efforts. Any other agreement, including alternative offerings, would remain illegal and expose the firms involved to risks of antitrust sanctions and liabilities. In the COORDINATION treatment, the two firms interacted in a one-stage coordinating mechanism in which both independently voted on whether or not to both sell the fair good. If both voted in favor, each offered the fair good to the consumer. If one or two firms voted against it, both firms chose the type of good independently (first stage of the market game.) In that case, the firms only learned about the kind of good offered by the other firm after both had made their choices regarding the kind of good. While we expect the same main results also with the coordination mechanism in Experiment 3, CSR collaboration should induce less unfair trade because by construction, firms cannot directly coordinate on both offering the unfair good.

We recruited students of the same mandatory Economics course in the UvA's PPLE bachelor as in Experiment 1, albeit one year later. In total, 136 students participated: 72 in treatment COORDINATION and 64 in treatment No COORDINATION, resulting in 432 and 384 per treatment respectively. Participants did not receive a show-up fee. They earned $€ 7.90$, on average, with a minimum of $€ 0$ and a maximum of $€ 13.60$. Like for Experiment 2, we pay special attention to the results of Experiment 3 that diverge from our findings in Experiment 1. Before we present the results, we note that the distributions of third-party preferences, plotted in Figure 1, do not differ significantly between Experiments 1 and 3 (two-sample combined Kolmogorov-Smirnov test, $\mathrm{p}=0.808) .{ }^{21}$ Any differences between the two experiments are directly attributable therefore to the differences in the coordination mechanism used.

\subsubsection{The Effect of CSR collaboration on Aggregate Market Outcomes}

Table 12 presents the aggregate outcomes of Experiment 3 and Table 13 presents random effect regressions on the type of goods traded, type of good offered, and market prices. As in Experiment

\footnotetext{
${ }^{21}$ In Experiment 3, consumers behaved in line with their third-party preferences in $77.12 \%$ of the selected observations. Third-party preferences revealed in part 1 predict a share of at least $52.70 \%$ of social responsible decisions while the externality was avoided in $46.79 \%$ of the market interactions. Like in Experiment 1, these differences are small and not statistically significant (Wilcoxon signed-rank test, $\mathrm{p}=0.184)$.
} 
1, the introduction of coordination possibilities does not affect the share of fair goods traded. Similarly, there are no significant differences in the share of unfair goods traded nor in the likelihood that the transaction occurs. The share of fair goods traded is not significantly different across both coordination mechanisms. In relation to the type of offers made by firms, in consonance with Experiment 1, firms tend to coordinate more on symmetric than on asymmetric offers when introducing coordination possibilities. ${ }^{22}$ Interestingly, the share of symmetric fair offers is not affected by CSR collaboration but the share of symmetric unfair offer is. Even though it is only possible to coordinate on symmetric fair offers, and an agreement is reached in less than half of the cases, the likelihood of a symmetric unfair offer significantly increases when introducing CSR collaboration.

Table 12: Type of goods traded, market prices, and offer types in Experiment 3

\begin{tabular}{|c|c|c|c|c|c|c|c|c|c|}
\hline Treatment & $\begin{array}{l}\text { Fraction } \\
\text { fair } \\
\text { goods } \\
\text { traded } \\
\end{array}$ & $\begin{array}{l}\text { Fraction } \\
\text { unfair } \\
\text { goods } \\
\text { traded } \\
\end{array}$ & $\begin{array}{l}\text { No } \\
\text { trade }\end{array}$ & $\begin{array}{l}\text { Fraction } \\
\text { fair goods } \\
\text { offered }\end{array}$ & $\begin{array}{l}\text { Fraction } \\
\text { Fair/Fair } \\
\text { offers }\end{array}$ & $\begin{array}{l}\text { Fraction } \\
\text { Unfair/Unfair } \\
\text { offers }\end{array}$ & $\begin{array}{l}\text { Fraction } \\
\text { Unfair/Fair } \\
\text { offers }\end{array}$ & $\begin{array}{l}\text { Price } \\
\text { fair } \\
\text { good }\end{array}$ & $\begin{array}{l}\text { Price } \\
\text { unfair } \\
\text { good }\end{array}$ \\
\hline $\begin{array}{l}\text { No } \\
\text { COORDINATION }\end{array}$ & $70.57 \%$ & $25.52 \%$ & $3.91 \%$ & $66.27 \%$ & $45.31 \%$ & $12.76 \%$ & $41.93 \%$ & 29.28 & 19.72 \\
\hline COORDINATION & $64.81 \%$ & $29.86 \%$ & $5.32 \%$ & $64.70 \%$ & $49.54 \%$ & $20.14 \%{ }^{* *}$ & $30.32 \% * * *$ & 29.56 & 16.73 \\
\hline $\mathbf{N}$ & 816 & 816 & 816 & 1632 & 408 & 408 & 408 & 551 & 227 \\
\hline
\end{tabular}

Notes: ${ }^{*} \mathrm{p}<0.1,{ }^{* *} \mathrm{p}<0.05,{ }^{* * *} \mathrm{p}<0.01$.

Table 13: Random effects regressions of type of goods traded, type of goods offered, and market prices in Experiment 3

\begin{tabular}{|c|c|c|c|c|c|c|}
\hline & $\begin{array}{l}\text { Fair good } \\
\text { traded } \\
(1) \\
\text { Logit }\end{array}$ & $\begin{array}{l}\text { Asymmetric } \\
\text { offer } \\
(2) \\
\text { Logit }\end{array}$ & $\begin{array}{l}\text { Fair/Fair } \\
\text { offer } \\
\text { (3) } \\
\text { Logit }\end{array}$ & $\begin{array}{l}\text { Unfair/Unfair } \\
\text { offer } \\
\text { (4) } \\
\text { Logit }\end{array}$ & $\begin{array}{l}\text { Price fair } \\
\text { good } \\
\text { (5) }\end{array}$ & $\begin{array}{l}\text { Price unfair } \\
\text { good } \\
(6)\end{array}$ \\
\hline Intercept & $\begin{array}{l}1.2398 \\
(0.2197)\end{array}$ & $\begin{array}{l}-0.4674 \\
(0.1745)\end{array}$ & $\begin{array}{l}-0.0170 \\
(0.1870)\end{array}$ & $\begin{array}{l}-2.1747^{* * *} \\
(0.2748)\end{array}$ & $\begin{array}{l}37.2650^{* * *} \\
(1.3791)\end{array}$ & $\begin{array}{l}25.1117^{* * *} \\
(25347)\end{array}$ \\
\hline COORDINATION & $\begin{array}{l}-0.3693 \\
(0.2350)\end{array}$ & $\begin{array}{l}-0.5068 * * * \\
(0.2007)\end{array}$ & $\begin{array}{l}0.1615 \\
(0.1948)\end{array}$ & $\begin{array}{l}0.6224^{* *} \\
(0.2564)\end{array}$ & $\begin{array}{l}-0.1244 \\
(1.4291)\end{array}$ & $\begin{array}{l}-1.6989 \\
(2.0689)\end{array}$ \\
\hline Period & $\begin{array}{l}-0.0161 \\
(0.0121)\end{array}$ & $\begin{array}{l}-0.0113 \\
(0.0118)\end{array}$ & $\begin{array}{l}-0.0134 \\
(0.0115)\end{array}$ & $\begin{array}{l}0.0020 \\
(0.0160)\end{array}$ & $\begin{array}{l}-0.6506^{* * *} \\
(0.0796)\end{array}$ & $\begin{array}{l}-0.4682^{* *} \\
(0.0954)\end{array}$ \\
\hline $\mathrm{N}$ & 816 & 408 & 408 & 408 & 551 & 227 \\
\hline
\end{tabular}

Notes: The dependent variable in (1) takes value 1 if the fair good is traded and 0 otherwise (unfair good traded or no transaction). Period takes values from 1 to 24. The dummy variable COORDINATION takes value 1 for the COORDINATION treatment. The models allow for individual-level random effects. Robust standard errors in parentheses (clustered by subject). ${ }^{*} p<0.1,{ }^{* *} p<0.05,{ }^{* * *} p<0.01$.

${ }^{22} 64 \%$ of the firms votes in favor of fair/fair; in $42 \%$ of the markets both firms did so. 
While firms are less likely to reach an agreement in Experiment 3's coordination mechanisms than in Experiment 1's, ${ }^{23}$ also in Experiment 3, the introduction of coordination possibilities does not affect prices for the fair or the unfair good. Again, we find that the firms' ability to coordinate has no significant impact on either consumer surplus or producer surplus. Consumer surplus, based on the third-party preferences measured in part 1 of the experiment, equals 133.52 [133.49] in the No COORDINATION [COORDINATION] treatment. Firm profits are equal to 77.56 [77.22] in the No COORDINATION [COORDINATION] treatment. Producer surplus, based on third-party preferences, equals 101.23 [101.20] in the No COORDINATION [COORDINATION] treatment.

\subsubsection{Firms' and Consumers' Individual Behavior}

Table 14 presents the results on consumer behavior in Experiment 3. Consistently with Experiment 1, the more participants cared about the third party, the more likely they were to avoid the externality when acting as consumers. Again, the ability of firms to coordinate does not affect the probability of the consumer avoiding the externality and third-party preferences do not affect the price paid for the fair good.

Table 14: Consumer behavior in Experiment 3

\begin{tabular}{|c|c|c|}
\hline & $\begin{array}{l}\text { Avoiding the } \\
\text { externality } \\
\text { (1) } \\
\text { Logit }\end{array}$ & $\begin{array}{c}\text { Fair good } \\
\text { purchased } \\
\text { (2) } \\
\text { Logit }\end{array}$ \\
\hline Intercept & $\begin{array}{c}0.5765 \\
(0.2933)\end{array}$ & $\begin{array}{c}-1.1293 \\
(1.7238)\end{array}$ \\
\hline Period & $\begin{array}{c}-0.0224 \\
(0.0137)\end{array}$ & $\begin{array}{c}-0.0581 \\
(0.0458)\end{array}$ \\
\hline 3rdPartyPref & $\begin{array}{c}0.0342^{* * * *} \\
(0.0080)\end{array}$ & $\begin{array}{c}0.2604^{* * *} \\
(0.0942)\end{array}$ \\
\hline COORDINATION & $\begin{array}{c}-0.3404 \\
(0.2697)\end{array}$ & $\begin{array}{l}-2.4546 \\
(1.5902)\end{array}$ \\
\hline PricediffFU & - & $\begin{array}{c}-0.3318^{* * *} \\
(0.0930)\end{array}$ \\
\hline $\mathrm{N}$ & 752 & 261 \\
\hline
\end{tabular}

Notes: The dependent variable in (1) takes value 1 if the fair good or no good is bought. Specification (2) restricts the analysis to observations where the consumer receives offers for both types of good. The dependent variable in (2) takes value 1 if the fair good is bought and 0 otherwise. PricediffFU is the difference in prices between the fair and unfair good when both goods are offered. Period takes values from 1 to 24. COORDINATION takes value 1 for the COORDINATION treatment. Observations where participants revealed inconsistent third-party preferences are excluded. The models allow for individual level random effects. Robust standard errors in parentheses (clustered by subject). ${ }^{*} p<0.1,{ }^{* *} p<0.05,{ }^{* * *} p<0.01$.

Table 15 includes regressions explaining firms' behavior in Experiment 3. Consistently with Experiment 1, the more participants care about the third party, the more likely they are to offer the fair good when acting as a firm. In this experimental setup, in which the firms cannot agree on product differentiation, we should not expect the fraction of fair goods to go up in the

\footnotetext{
${ }^{23}$ The likelihood is $80.56 \%$ and $42.13 \%$ in Experiments 1 and 3 respectively $(\mathrm{p}=0.000)$.
} 
subsample of firms with weak social preferences matched. In line with previous experiments, CSR collaboration does not induce firms with strong third-party preferences to both offer the fair good. Due to the coordination mechanism, firms cannot coordinate explicitly on both offering the unfair product, nor on product differentiation when both offer the unfair product in competition, so we cannot replicate specification (2) in Table 7. Unfortunately, however, we cannot test whether this may be due to pairs of unconditionally selfish firms no longer being able to use the collaboration to product differentiate by replicating specification (3) in Table 7: We have no observations in the No COORDINATION treatment where both firms matched in the same market are unconditionally selfish. Specification (5) does provide weak evidence that, when coordination (only on fair offers) is possible, the fraction of unfair/unfair offers increases in a subsample where both firms are not unconditionally selfish or altruistic. This observation contributes to understanding the finding that CSR collaboration has a negative impact on product variety, i.e. Result 2.

Table 15: Firms' behavior in Experiment 3

\begin{tabular}{|c|c|c|c|c|}
\hline & $\begin{array}{c}\text { Fair good } \\
\text { offered } \\
(1) \\
\text { Logit } \\
\end{array}$ & $\begin{array}{c}\text { Unfair/fair } \\
\text { offer } \\
(3) \\
\text { Logit }\end{array}$ & $\begin{array}{c}\text { Fair/Fair } \\
\text { offer } \\
(4) \\
\text { Logit } \\
\end{array}$ & $\begin{array}{c}\text { Unfair/Unfair } \\
\text { offer } \\
\text { (5) } \\
\text { Logit } \\
\end{array}$ \\
\hline Intercept & $\begin{array}{c}-1.5847^{* *} \\
(0.7075)\end{array}$ & - & $\begin{array}{c}0.8203^{* * *} \\
(0.3000)\end{array}$ & $\begin{array}{c}0.3848 \\
(0.7233)\end{array}$ \\
\hline Period & $\begin{array}{c}-0.0075 \\
(0.0168)\end{array}$ & - & $\begin{array}{l}-0.0135 \\
(0.0229)\end{array}$ & $\begin{array}{c}0.0017 \\
(0.0202)\end{array}$ \\
\hline 3rdPartyPref & $\begin{array}{c}0.0889 * * * \\
(0.0179)\end{array}$ & - & - & $\begin{array}{c}-0.0558^{* * *} \\
(0.0154)\end{array}$ \\
\hline 3rdPartyPrefOther & - & - & - & $\begin{array}{c}-0.0483^{* * *} \\
(0.0100)\end{array}$ \\
\hline COORDINATION & $\begin{array}{c}0.0940 \\
(0.4831)\end{array}$ & - & $\begin{array}{c}0.2157 \\
(0.3251)\end{array}$ & $\begin{array}{c}0.7426^{*} \\
(0.4484)\end{array}$ \\
\hline $\mathrm{N}$ & 1528 & - & 190 & 506 \\
\hline
\end{tabular}

Notes: The dependent variable in (1) takes value 1 if the fair good is offered. Period takes values from 1 to 24 . COORDINATION takes value 1 for the COORDINATION treatment. (3) is restricted for observations where both firms in the same market are unconditionally selfish i.e. 3rdPartyPref $=2.1875$ - the estimates for this specification does not exist because there are no observations in the No COORDINATION treatment where both firms matched in the same market are unconditionally selfish. Specification (4) is restricted for observations where both firms in the same market are unconditionally altruistic i.e. 3rdPartyPref $=43.75$. Specification (5) is restricted to the remaining observations. Observations where participants revealed inconsistent third-party preferences are excluded. The models allow for individual level random effects. Robust standard errors in parentheses (clustered by subject). ${ }^{*} p<0.1,{ }^{* *} p<0.05,{ }^{* * *} p<0.01$

We conclude that the findings in the baseline experiment seem not primarily driven by a looser coordination than may be allowed by a competition authority in practice. This further supports the suggestion given by the main experiment that a broad relaxation of the cartel prohibition does not appear to be inducive to more CSR efforts. 


\section{Conclusion}

In an experiment designed to study the effectiveness of allowing CSR agreements, we find no significant effect of CSR collaboration on the fraction of fair goods traded, average market prices, producer surplus, and consumer surplus in the full sample. In fact, product variety somewhat decreases as the firms coordinate more often on offering the same product type, either fair or unfair. We do expect and find that collaboration amongst firms that care little about the negative externality that their production causes increased product differentiation on the CSR dimension. Such selfish firms offer the unfair good in competition and take the opportunity to collaborate to differentiate their products by one of them offering the 'fair' good. This is profitable for them, as it softens subsequent price competition. Participants' social values are found to be a powerful predictor for consumers purchasing the fair good. Similarly, firms are more likely to offer the fair good the stronger their third-party preferences, which is in line with the classic 'upper echelons perspective' in the management literature. Yet the presence of firms that have sufficiently strong third-party preferences makes that products are already either differentiated, or all fair in competition, in which cases CSR agreements do not increase the fraction of fair goods offered. This partly explains why allowing CSR agreements has no effects on average in the diverse total sample.

These main findings are corroborated in two additional experiments, one with a diffused negative externality, resulting in weaker third-party preferences, and one with a stricter policy control, by allowing the firms only to coordinate on the fair good. With the diffused negative externality, only the price of the fair good was somewhat lower. With the firms restricted to explicit coordination on both offering the fair good only, they reached an agreement by CSR collaboration less often, while the likelihood of both firms offering an unfair good was higher. Allowing firms to coordinate their CSR efforts did not result in more fair production overall. Our experimental results suggest that CSR collaboration may even induce firms to collude on less CSR than they otherwise would in competition. We conclude that in the a-select wide population to which the treatment was applied, the fraction of combinations of unconditionally selfish firms is too small to increase the overall fraction of fair products offered significantly.

We interpret our experiments as conservative tests of the policy proposals to allow firms to coordinate their CSR activities, because we carefully controlled for the way firms could coordinate their activities by only allowing them to communicate about the kind of goods offered. In practice, an associated risk is that allowing CSR collaboration provides the firms a platform to collude on other dimensions of competition as well, including on higher prices, less production capacity, or less R\&D. This has been observed in industries in which R\&D joint ventures were allowed (Duso et al., 2014; Sovinsky, 2022). A case in point is Consumer Detergents, in which producers of 
washing powders used an accredited industry-wide initiative to promote more concentrated, and therefore environmentally friendlier doses and packages as a cover for price collusion. ${ }^{24}$ Despite that participants on experiment could not collude beyond the product type, we find hints in our data of the joint CSR standard setting also affecting pricing decisions. For example may it be indicative of tacit collusion that, while product homogeneity goes up under collusion, so that stronger price competition should follow, we find that prices stay roughly the same. ${ }^{25}$

Our findings warrant skepticism about the desirability of granting exemptions from the cartel prohibition under general conditions for agreements amongst competitors that claim to improve CSR efforts. They suggest that CSR collaboration should only be expected to increase CSR efforts if there are enough firms that do not care to act responsibly in competition and therefore can profit from coordinating on differentiated, somewhat more responsible business. In that case, consumers pay higher prices and are harmed on balance, despite their appreciation for CSR. We find no or negative effects on CSR effort in the wider set of managerial and consumer values. If CSR collaborations are to be exempted from cartel law, our findings suggest this best is case-bycase bespoke antitrust policy, and not a broad cartel exemption possibility. Yet it is questionable whether competition authorities have the means to identify and only exempt CSR agreements amongst unconditionally selfish companies, given the generality of the exemption requirements. Instead, our findings suggest that more awareness of the importance of CSR with consumers and managers contributes more to socially responsible behavior than opportunities for firms to coordinate their CSR activities. Indeed, there are signs that consumer willingness-to-pay for sustainably produced goods is growing (see, e.g., Delmas \& Colgan, 2018).

Nevertheless, our results are preliminary. Further research should study the effect of the distribution of managerial preferences, for instance by using a selected pool of participants in the role of firm with known low third-party preferences, i.e. high unconditional selfishness, may give further insight in the strength of our results that only amongst this 'grey' type of firms should CSR collaboration be expected to improve CSR efforts. Such further studies may also shed more light on the balance of harm to consumers. Moreover, our experiments are based on a setting with two firms and one consumer. Based on what is known from the experimental literature, we would not expect that adding firms or consumers would significantly affect our results, but this can be studied more carefully in future experiments. Another question that we leave for future research is why CSR collaboration induces firms to coordinate more frequently on unfair/unfair outcomes, which does not follow from our present theory. It would also be interesting to consider more

\footnotetext{
${ }^{24}$ Consumer Detergents (2011). Commission Decision, Case COMP/39579 - Consumer Detergents, April 13. ${ }^{25}$ In Experiment 1, in the COORDINATION treatment, when consumers face symmetric fair offers, the price offered by firms for the fair good is 31.34 when an agreement is reached and 23.95 when not. The difference is statistically significant at the $5 \%$ level.
} 
firms that can product differentiate by offering various degrees of fairer goods. Other potentially interesting extensions include allowing participants to communicate more broadly in the context of being allowed to coordinate CSR activities. While this may induce them to collude on other dimensions of competition, it may also reveal wider circumstances under which public interests are truly promoted by private collusion than just among the selfish firms where we found some.

\section{References}

ACM (2021). Draft Guidelines Sustainability Agreements: Opportunities within Competition Law, 26 January 2021.

Adler, J. H. (2004). Conservation cartels: Competition policy can conflict with environmental protection. Regulation 27(4), 38-46.

Aghion, P., Bénabou, R., Martin, R., \& Roulet, A. (2022). Environmental preferences and technological choices: Is market competition clean or dirty? American Economics Review: Insights, forthcoming

Agle, B.R., Mitchell, R.K, \& Sonnenfeld, J.A. (1999). Who matters to CEOs? An investigation of stakeholder attributes and salience, corporate performance, and CEO values. Academy of Management Journal 42, 507-525.

Ahmed, R. \& Segerson, K. (2011). Collective voluntary agreements to eliminate polluting products. Resource and Energy Economics, 33(3), 572-588.

Alberini, A. \& Segerson, K. (2002). Assessing voluntary programs to improve environmental quality. Environmental and Resource Economics 22, 157-184.

Baron, D. P. (2001). Private politics, corporate social responsibility, and integrated strategy. Journal of Economics \& Management Strategy 10(1), 7-45.

Bartling, B., Weber, R.A., \& Yao, L. (2015). Do markets erode social responsibility? The Quarterly Journal of Economics 130(1), 219-266.

Bartling, B., Valero, V., \& Weber, R. (2017). On the scope of externalities in experimental markets. Experimental Economics 20,1-15.

Bénabou, R., \& Tirole, J. (2010). Individual and corporate social responsibility. Economica 77(305), 1-19. 
Brekke, K. R., Holmås, T. H., Monstad, K., \& Straume, O. R. (2019). Competition and physician behaviour: Does the competitive environment affect the propensity to issue sickness certificates? Journal of Health Economics 66, 117-135.

Cai, H. \& Liu, Q. (2009). Competition and corporate tax avoidance: Evidence for Chinese industrial firms. Economic Journal 119, 764-795.

Chin, M.K., Hambrick, D.C., \& Treviño, L.K. (2013). Political ideologies of CEOs: The influence of executives' values on corporate social responsibility. Administrative Science Quarterly 58(2), 197-232.

Colombo, L., \& Labrecciosa, P. (2018). Consumer surplus-enhancing cooperation in a natural resource oligopoly. Journal of Environmental Economics and Management 92, 185-193.

Dewatripont, M. \& Tirole, J. (2022) The Morality of Markets and the Nature of Competition, Paper presented at the Markets and Morals Paper Session at the AEA meeting, January 8, 2022.

Davis, D.D., \& Wilson, B.J. (2008). Strategic buyers, horizontal mergers and synergies: An experimental investigation. International Journal of Industrial Organization 26, 643-661.

Delmas, M. A. \& Colgan, D. (2018). The Green Bundle. Stanford University Press.

Du, S., Bhattacharya, C. B., \& Sen, S. (2011). Corporate social responsibility and competitive advantage: Overcoming the trust barrier. Management Science 57(9), 1528-1545.

Duanmu, J.-L., Bu, M. \& Pittman, R. (2015). Does market competition dampen environmental performance? Evidence from China. Strategic Management Journal 39, 3006-3030.

Duso, T., Röller, L. \& Seldeslachts, J. (2014). Collusion through joint R\&D: An empirical assessment. Review of Economics and Statistics 96(2), 349-370.

Engelmann, D., Friedrichsen, J., \& Kübler, D. (2018). Fairness in markets and market experiments. WZB Discussion Paper.

European Commission (2021). Competition Policy in Support of Europe's Green Ambition. Competition policy brief, September 2021.

European Commission (2022), Draft Guidelines on the applicability of Article 101 of the Treaty on the Functioning of the European Union to horizontal co-operation agreements, Brussels, March 1.

Falk, A., \& Szech, N. (2013). Morals and markets. Science 340(6133), 707-711. 
Fehr, E., \& Schmidt, K.M. (1999). A theory of fairness, competition, and cooperation. The Quarterly Journal of Economics 114(3), 817-868.

Fernández-Kranz, D. \& Santaló, J. (2010). When necessity becomes a virtue: The effect of product market competition on corporate social responsibility. Journal of Economics \& Management Strategy 19(2), 453-487.

Filistrucchi, L., \& Prüfer, J. (2019). Faithful strategies: How religion shapes nonprofit management. Management Science 65(1), 188-208.

Flammer, C. (2015). Does product market competition foster corporate social responsibility? Evidence from trade liberalization. Strategic Management Journal 36(10), 1469-1485

Fonseca, M.A., \& Normann, H.T. (2012). Explicit vs. tacit collusion-The impact of communication in oligopoly experiments. European Economic Review 56(8), 1759-1772.

Gomez-Martinez, F., Onderstal, S., \& Sonnemans, J. (2016). Firm-specific information and explicit collusion in experimental oligopolies. European Economic Review 82, 132-141.

Hambrick, D.C., \& Mason, P.A. (1984). Upper echelons: The organization as a reflection of its top managers. Academy of Management Review 9, 193-206.

Henderson (2020). Reimagining capitalism in a world on fire, Public Affairs.

Hinloopen, J., Onderstal, S., \& Treuren, L. (2020). Cartel stability in experimental first-price sealedbid and English auctions. International Journal of Industrial Organization 71, 102642.

Isaac, R.M., Ramey, V., \& Williams, A.W. (1984). The effects of market organization on conspiracies in restraint of trade. Journal of Economic Behavior \& Organization 5(2), 191-222.

Kirchler, M., Huber, J., Stefan, M., \& Sutter, M. (2016). Market design and moral behavior. Management Science 62, 2615-2625.

Kotchen, M. J. \& Segerson, K. (2019). On the use of group performance and rights for environmental protection and resource management. Proceedings of the National Academy of Sciences 116(12), 5285-5292.

Krajewski, M. (2014). The great lightbulb conspiracy. IEEE spectrum, 51(10), 56-61.

Kube, R., Löschel, A., Mertens, H., \& Requate, T. (2018). Research trends in environmental and resource economics: Insights from four decades of JEEM. Journal of Environmental Economics and Management 92, 433-464. 
Kurtyka, O., \& Mahenc, P. (2011). The switching effect of environmental taxation within Bertrand differentiated duopoly. Journal of Environmental Economics and Management 62(2), 267-277.

Lee, J.H., Byun, H.S., \& Park, K.S. (2018). Product market competition and corporate social responsibility activities: Perspectives from an emerging economy. Pacific-Basin Finance Journal $49,60-80$.

List, J. A. (2020). Non est disputandum de generalizability? A glimpse into the external validity trial. Technical report, National Bureau of Economic Research.

Lyon, T.P. \& Maxwell, J.W. (2004). Corporate environmentalism and public policy. Cambridge University Press, Cambridge.

Markussen, S., \& Røed, K. (2017). The market for paid sick leave. Journal of Health Economics 55, 244-261.

Marquis, C., \& Lee, M. (2013). Who is governing whom? Executives, governance, and the structure of generosity in large U.S. firms. Strategic Management Journal 34, 483-497.

Maxwell, J.W., Lyon, T.P. \& Hackett, S.C. (2000). Self-regulation and social welfare: The political economy of corporate environmentalism. Journal of Law \& Economics 43, 583-617.

McWilliams, A. \& Siegel, D. (2001), Corporate Social Responsibility: a Theory of the Firm Perspective, Academy of Management Review 26(1), 117-127.

Orland, A., \& Selten, R. (2016). Buyer power in bilateral oligopolies with advance production: Experimental evidence. Journal of Economic Behavior \& Organization 122, 31-42.

Pigors, M., \& Rockenbach, B. (2016). Consumer social responsibility. Management Science 62, 3123-3137.

Polman, P. \& A. Winston (2021). Net Positive: How Courageous Companies Thrive by Giving More Than They Take. Harvard Business Review Press.

Porter, M.E. \& M.R Kramer (2006), Strategy and Society: The Link between Competitive Advantage and Corporate Social Responsibility, Harvard Business Review 84(12), 78-92.

Potters, J., \& Suetens, S. (2013). Oligopoly experiments in the current millennium. Journal of Economic Surveys 27(3), 439-460.

Rode, J., Hogarth, R. M., \& Le Menestrel, M. (2008). Ethical differentiation and market behavior: An experimental approach. Journal of Economic Behavior \& Organization 66, 265-280. 
Roth, A.E., Prasnikar, V., Okuno-Fujiwara, M., \& Zamir, S. (1991). Bargaining and market behavior in Jerusalem, Ljubljana, Pittsburgh and Tokyo: An experimental study. American Economic Review 81, 1068-1095.

Schinkel, M.P., \& Spiegel, Y. (2017). Can collusion promote sustainable consumption and production? International Journal of Industrial Organization 53, 371-398.

Schinkel, M.P. \& Treuren, L. (2021a), Green Antitrust: Friendly Fire in the Fight against Climate Change, in: Holmes, S., D. Middelschulte \& M. Snoep (eds.), Competition Law, Climate Change \& Environmental Sustainability, Concurrences.

Schinkel, M.P. \& Treuren, L. (2021b). Corporate social responsibility by joint agreement. Tinbergen Institute Discussion Paper 2021-063/VII.

Schram, A. (2005). Artificiality: The tension between internal and external validity in economic experiments. Journal of Economic Methodology 12, 225-237.

Scott (2016). Antitrust and socially responsible collaboration: A chilling combination, American Business Law Journal, 53 (1), 97-144.

Shaked, A., \& Sutton, J. (1982). Relaxing price competition through product differentiation. The Review of Economic Studies 49, 3-13.

Shleifer, A. (2004). Does competition destroy ethical behavior? American Economic Review Papers and Proceedings 94, 414-418.

Simon, D. H., \& Prince, J. T. (2016). The effect of competition on toxic pollution releases. Journal of Environmental Economics and Management 79, 40-54.

Soetevent, A.R., Bao, T., \& Schippers, A.L. (2016). A Commercial Gift for Charity. Tinbergen Institute Discussion Paper 2016-009/VII.

Solow, R.M. (1974). The economics of resources and the resources of economics. American Economic Review, Papers and Proceedings 64, 1-14.

Sovinsky, M. (2022) Do research joint ventures serve a collusive function? Journal of the European Economic Association 20(1), 430-475.

Sutter, M., Huber, J., Kirchler, M., Stefan, M., \& Walzl, M. (2020). Where to look for the morals in markets? Experimental Economics 23(1), 30-52. 
Tyran, J.R., \& Engelmann, D. (2005). To buy or not to buy? An experimental study of consumer boycotts in retail markets. Economica 72(285), 1-16.

Werden, G.J. (2014). Antitrust's rule of reason: Only competition matters. Antitrust Law Journal, 79, 713-723.

Yang, Y., Onderstal, S. \& Schram, A. (2016). Inequity aversion revisited. Journal of Economic Psychology 54, 1-16.

Zhang, R., Zhu, J., Yue, H. \& Zhu, C. (2010). Corporate philanthropic giving, advertising intensity, and industry competition level. Journal of Business Ethics 94(1), 39-52.

Ziegler, A., Romagnoli, G., \& Offerman, T. (2020). Morals in multi-unit markets. Tinbergen Institute Discussion Paper 2020-072/I. 


\section{Appendix A: Complementary theoretical analysis}

\section{A.1. Proofs of Propositions}

Proof of Proposition 1. We solve the game using backward induction. Assume for the moment that both the fair and the unfair goods are offered at 'moderate' prices so that the consumer always buys a good, sometimes buying the fair good and sometimes buying the unfair good (it is readily verified that the equilibrium prices satisfy those assumptions under Assumption A1). If both firms offer the same good, the Bertrand logic applies, resulting in marginal-cost pricing in equilibrium. If the firms offer a different good, the type- 0 firm, selling the unfair good, solves

$$
p^{u} \in \operatorname{argmax}_{p}\left\{P\left\{\gamma<p^{f}-p\right\}\left(p-c^{u}\right)\right\}=\left\{\frac{p^{f}+c^{u}}{2}\right\}
$$

when best-responding to the other firm choosing a price $p^{f} \in\left(c^{u}, 2 \bar{\gamma}+c^{u}\right)$. The type- $\bar{\varphi}$ firm, selling the fair good, solves

$$
\begin{gathered}
p^{f} \in \operatorname{argmax}_{p}\left\{P\left\{\gamma \geq p-p^{u}\right\}\left(p-c^{f}\right)-P\left\{\gamma<p-p^{u}\right\} \bar{\varphi}\right\} \\
=\left\{\frac{\bar{\gamma}+p^{u}+c^{f}-\bar{\varphi}}{2}\right\}
\end{gathered}
$$

for $p^{u} \in\left(c^{f}-\bar{\varphi}-\bar{\gamma}, c^{f}-\bar{\varphi}+\bar{\gamma}\right)$. Solving for the equilibrium prices yields

$$
\begin{gathered}
p^{f}=\frac{2 c^{f}+c^{u}-2 \bar{\varphi}+2 \bar{\gamma}}{3} \\
p^{u}=\frac{c^{f}+2 c^{u}-\bar{\varphi}+\bar{\gamma}}{3} .
\end{gathered}
$$

The conditions $c^{u} \leq c^{f}$ and Assumption $\mathbf{A} 2$ ensure that both firms sell a strictly positive quantity at the proposed equilibrium prices, which, in turn, implies that both firms indeed maximize profits at those prices.

Now, we check if in the first stage, the two firms types separate in equilibrium. For 0-type firms, the expected profits equal

$$
\pi_{u}=\alpha\left(p^{u}-c^{u}\right) P\left\{\gamma<p^{f}-p^{u}\right\}=\alpha \frac{\left(c^{f}-c^{u}-\bar{\varphi}+\bar{\gamma}\right)^{2}}{9 \bar{\gamma}}
$$

If it deviates by producing the fair good, its optimal price when the other firm has type $\varphi_{i}=0$ is equal to $\tilde{p}^{f}=\frac{4 c^{f}+2 c^{u}-\bar{\varphi}+4 \bar{\gamma}}{6}$. The resulting expected profits are

$$
\tilde{\pi}_{f}=(1-\alpha) \frac{\left(2 c^{u}-2 c^{f}-\bar{\varphi}+4 \bar{\gamma}\right)^{2}}{36 \bar{\gamma}} .
$$


By Assumption A3, a type-0 firms has no reason to deviate because

$$
\begin{gathered}
\pi_{u} \geq \tilde{\pi}_{f} \Leftrightarrow \\
\alpha \geq \frac{\left(2 c^{u}-2 c^{f}-\bar{\varphi}+4 \bar{\gamma}\right)^{2}}{\left(2 c^{u}-2 c^{f}-\bar{\varphi}+4 \bar{\gamma}\right)^{2}+4\left(c^{f}-c^{u}-\bar{\varphi}+\bar{\gamma}\right)^{2}}=\underline{\alpha .}
\end{gathered}
$$

A $\bar{\varphi}$-type firm has no reason to deviate to producing the unfair good if, when the other firm produces the fair good, it can only get a strictly positive market share at a price

$$
\tilde{p}^{u}<p^{f}(\bar{\varphi})=\frac{2 c^{f}+c^{u}-2 \bar{\varphi}+2 \bar{\gamma}}{3} \leq c^{u}+\bar{\varphi}
$$

where the latter equation follows from the assumption that $\bar{\varphi} \geq \frac{2}{5}\left(\bar{\gamma}+c^{f}-c^{u}\right)$ (Assumption A2). However, when the firms sells at a price $\tilde{p}^{u}$, it incurs $\operatorname{costs} c^{u}$ and the negative externality $\bar{\varphi}$ so that it is strictly better off letting the other firm sell the fair good.

Proof of Proposition 2. Using backward induction, and the equilibrium prices derived in the proof of Proposition 1, it is readily verified that the strategies displayed constitute a subgame perfect equilibrium. The second-mover type- 0 firm has no reason to deviate and reject the firstmover's fair-unfair proposal. Deviating from it will yield profits $\tilde{\pi}_{f}$ in the proof of Proposition 1 for $\alpha=0$ so that we obtain

$$
\tilde{\pi}_{f}=\frac{\left(2 c^{u}-2 c^{f}-\bar{\varphi}+4 \bar{\gamma}\right)^{2}}{36 \bar{\gamma}} \leq \frac{\left(c^{f}-c^{u}+\bar{\gamma}\right)^{2}}{3 \bar{\gamma}}=P\left\{\gamma \leq p^{f}(0)-p^{u}(0)\right\}\left(p^{u}(0)-c_{u}\right)=\pi_{u}
$$

where the inequality follows from Assumption $\mathbf{A 4}$ and where $\pi_{u}$ displays the second-mover's profits when accepting the first-mover's proposal.

Proof of Proposition 3. Parts (i) - (iv) follow straightforwardly from the results presented in Table 1. To prove part (v), notice from Table 1 that the market game and the collaboration game only have a different equilibrium outcome, and hence consumer surplus, if $\varphi_{1}=\varphi_{2}=0$. In that scenario, let $\gamma^{*} \equiv p^{f}(0)-p^{u}(0)$ be the consumer type that is indifferent between buying the fair good and the unfair good in the collaboration game under the equilibrium prices. All consumer types for whom $\gamma<\gamma^{*}$ are strictly worse off in the collaboration game than in the market game because in both games they buy the unfair good in equilibrium paying a higher price in the collaboration game. Consumer types $\gamma>\gamma^{*}$ buy the fair good in the collaboration game and the unfair good in the market game. On the average, given $\gamma>\gamma^{*}$, consumer surplus in the market game $\left(C S^{\text {market }}\right)$ is greater than consumer surplus in the collaboration game $\left(C S^{\text {coll }}\right)$ :

$$
C S^{\text {market }}=v-c^{u}-E\left\{\gamma \mid \gamma>\gamma^{*}\right\}
$$




$$
\begin{gathered}
=v-c^{u}-\frac{\gamma^{*}+\bar{\gamma}}{2} \\
=v-c^{u}-\frac{p^{f}(0)-p^{u}(0)+\bar{\gamma}}{2} \\
=v-c^{u}+\frac{p^{f}(0)+p^{u}(0)-\bar{\gamma}}{2}-p^{f}(0) \\
=v-c^{u}+\frac{c^{f}+c^{u}}{2}-p^{f}(0) \\
\geq v-p^{f}(0)=C S^{c o l l}
\end{gathered}
$$

The inequality follows from the assumption that $c^{u} \leq c^{f}$.

\section{A.2: Additional theoretical results}

In this appendix, we derive results under the standard assumption that neither firm internalizes the negative externality, i.e., $\alpha=0$. The market game then boils down to a standard vertical product differentiation model. It has a symmetric mixed-strategy equilibrium, described in Proposition A.1, in which both firms randomize over offering the fair good and the unfair good.

Proposition A.1. If $\alpha=0$, the market game has a symmetric subgame perfect Nash equilibrium in mixed strategies in which firm $i$ produces the fair good with probability $q^{f} \equiv$ $\frac{\left(c^{u}-c^{f}+2 \bar{\gamma}\right)^{2}}{\left(c^{u}-c^{f}+2 \bar{\gamma}\right)^{2}+\left(c^{f}-c^{u}+\bar{\gamma}\right)^{2}} i=1$, 2. If both firms produce the unfair good, then $p_{1}=p_{2}=c^{u}$. If both firms produce the fair good then $p_{1}=p_{2}=c^{f}$. If firm $i$ produces the fair good and firm $j \neq i$ produces the unfair good then firm i's and firm j's equilibrium prices are

$$
\begin{aligned}
& p_{i}=p^{f} \equiv \frac{2 c^{f}+c^{u}+2 \bar{\gamma}}{3} \\
& p_{j}=p^{u} \equiv \frac{c^{f}+2 c^{u}+\bar{\gamma}}{3}
\end{aligned}
$$

respectively.

Proof of Proposition A.1. We solve the game using backward induction. Assume for the moment that both the fair and the unfair goods are offered at 'moderate' prices so that consumers always buy a good and that some buy the fair good and some buy the unfair good (it is readily verified that the equilibrium prices satisfy those assumptions). In the case that both firms offer the same 
good, the Bertrand logic applies, resulting in (close to) marginal-cost pricing in equilibrium. If the firms offer a different good, the one selling the unfair good solves

$$
\begin{aligned}
p^{u} \in \operatorname{argmax}_{p} & \left\{P\left\{\gamma<p^{f}-p\right\}\left(p-c^{u}\right)+P\left\{\gamma \geq p^{f}-p\right\} \varphi_{i}\right\} \\
= & \left\{\frac{p^{f}+c^{u}+\varphi_{i}}{2}\right\}
\end{aligned}
$$

when best-responding to the other firm choosing a price $p^{f} \in\left(c^{u}+\varphi_{i}, 2 \bar{\gamma}+c^{u}+\varphi_{i}\right)$. The firm selling the fair good solves

$$
p^{f} \in \operatorname{argmax}_{p}\left\{P\left\{\gamma \geq p-p^{u}\right\}\left(p-c^{f}+\varphi_{i}\right)\right\}=\left\{\frac{\bar{\gamma}+p^{u}+c^{f}-\varphi_{i}}{2}\right\}
$$

for $p^{u} \in\left(c^{f}-\varphi_{i}-\bar{\gamma}, c^{f}-\varphi_{i}+\bar{\gamma}\right)$. Solving the two equations for $p^{u}$ and $p^{f}$ yields the equilibrium prices (A.8) and (A.9). The firms' resulting profits are

$$
\pi_{i}=\pi^{f} \equiv \frac{\left(c^{u}-c^{f}+2 \bar{\gamma}\right)^{2}}{9 \bar{\gamma}} ; \pi_{j}=\pi^{u} \equiv \frac{\left(c^{f}-c^{u}+\bar{\gamma}\right)^{2}}{9 \bar{\gamma}}
$$

\begin{tabular}{|c|c|c|c|}
\hline \multirow{3}{*}{ iirm 2} & \multirow{3}{*}{$\begin{array}{l}\text { Fair } \\
\text { Unfair }\end{array}$} & Fair & Unfair \\
\hline & & 0,0 & $\pi^{f}, \pi^{u}$ \\
\hline & & $\pi^{u}, \pi^{f}$ & 0,0 \\
\hline
\end{tabular}

respectively. The first stage then reduces to the following $2 \times 2$ game

\section{Firm 1}

This game has a unique symmetric mixed-strategy equilibrium in which a firm chooses the fair good with probability $\frac{\pi^{f}}{\pi^{f}+\pi^{u}}=\frac{\left(c^{u}-c^{f}+2 \bar{\gamma}\right)^{2}}{\left(c^{u}-c^{f}+2 \bar{\gamma}\right)^{2}+\left(c^{f}-c^{u}+\bar{\gamma}\right)^{2}}=q^{f}$.

Proposition A.2. If $\varphi_{i}=0, i=1,2$, the following strategies constitute a subgame-perfect equilibrium of the extended market game. When it is a firm's turn to make a proposal, it proposes offering the unfair [fair] good itself and the other firm offering the fair [unfair] good if $\pi^{u} \geq \pi^{f}$ $\left[\pi^{u}<\pi^{f}\right]$. The firms accept asymmetric proposals and reject symmetric ones in the first stage and reject all proposals in the second stage. If a proposal is accepted, firms choose prices according to equations (A.8) and (A.9) in Proposition A.1. If both proposals are rejected, the firms play the asymmetric equilibrium of the market game where the first mover offers the unfair [fair] good and the other firm offers the fair [unfair] good if $\pi^{u} \geq \pi^{f}\left[\pi^{u}<\pi^{f}\right]$. 
Proof of Proposition A.2. Using backward induction, and the equilibrium prices derived in the proof of Proposition A.1, it is readily verified that the strategies displayed constitute a subgame perfect equilibrium

Proposition A.3. Suppose $\varphi_{i}=0, i=1,2$. CSR collaboration

(i) increases the likelihood that the fair good is traded;

(ii) increases product variety;

(iii) has a positive effect on prices for the fair good and the unfair good;

(iv) increases producer surplus;

(v) decreases consumer surplus.

Proof of Proposition A.3. Parts (i) - (iv) follow straightforwardly from Propositions A.1 and A.2. The difference in consumer surplus between the asymmetric equilibrium and the symmetric equilibrium is given by

$$
\begin{aligned}
& \Delta C S=\int_{\underline{\gamma}}^{\bar{\gamma}}\left(\left(q^{f}\right)^{2}\left(c^{f}-p^{f}\right)+\left(1-q^{f}\right)^{2}\left(\gamma-p^{f}+c^{u}\right)\right) d \gamma \\
& +\int_{0}^{\underline{\gamma}}\left(\left(q^{f}\right)^{2}\left(c^{f}-\gamma-p^{u}\right)+\left(1-q^{f}\right)^{2}\left(c^{u}-p^{u}\right)\right) d \gamma \\
& \leq \int_{\underline{\gamma}}^{\bar{\gamma}}\left(1-q^{f}\right)^{2}\left(\gamma-p^{f}+c^{u}\right) d \gamma+\int_{0}^{\underline{\gamma}}\left(q^{f}\right)^{2}\left(c^{f}-\gamma-p^{u}\right) d \gamma \\
& =\left(1-q^{f}\right)^{2}(\bar{\gamma}-\underline{\gamma})\left(\frac{\bar{\gamma}}{2}+\frac{\underline{\gamma}}{2}-p^{f}+c^{u}\right)+\left(q^{f}\right)^{2} \underline{\gamma}\left(c^{f}-\frac{\bar{\gamma}}{2}-p^{u}\right)<0 \text {, }
\end{aligned}
$$

where $\underline{\gamma}=p^{f}-p^{u}$ is the consumer type that is indifferent between buying the fair good and the unfair good when both are offered at the equilibrium prices. The first [second] term on the RHS of the first equality refers to consumer types $\gamma$ who buy the [un]fair good at the equilibrium prices if both goods are offered to the market. The first inequality follows because $c^{f}<p^{f}$ and $c^{u}<p^{u}$. The second inequality follows from $\underline{\gamma}=p^{f}-p^{u}$ and $p^{f}+p^{u}=c^{f}+c^{u}+\bar{\gamma}$. 


\section{Appendix B: Pooled analysis of the three experiments}

In this appendix, we replicate the results for Experiments 1-3 pooling the data of the three experiments. Tables B.1-B.4 mirror tables 3, 4, 6, and 7 in the main text. The results are consistent with the ones obtained in Experiment 1, with the following exceptions:

- In contrast to what is reported in Result 3, in the pooled data, the price of the fair good is significantly lower in the COORDINATION treatment than in the No COORDINATION treatment; Hypothesis 3(a) is still rejected.

- In contrast to what is reported in Result 6, in the pooled data, unconditionally selfish firms do not differentiate significantly more often their product in the COORDINATION treatment.

- Firms with intermediate third-party preferences offer more often symmetric unfair offers when considering all the data pulled (see table B.4 specification (5)).

Table B.1 : Type of goods traded, market prices, and offer types in all experiments ${ }^{26}$

\begin{tabular}{lllllllll}
\hline Treatment & $\begin{array}{l}\text { Fraction } \\
\text { fair } \\
\text { goods } \\
\text { traded }\end{array}$ & $\begin{array}{l}\text { Fraction } \\
\text { unfair } \\
\text { goods } \\
\text { traded }\end{array}$ & $\begin{array}{l}\text { No } \\
\text { trade }\end{array}$ & $\begin{array}{l}\text { Fraction } \\
\text { Fair/Fair } \\
\text { offers }\end{array}$ & $\begin{array}{l}\text { Fraction } \\
\text { Unfair/Unfair } \\
\text { offers }\end{array}$ & $\begin{array}{l}\text { Fraction } \\
\text { Unfair/Fair } \\
\text { offers }\end{array}$ & $\begin{array}{l}\text { Price } \\
\text { fair } \\
\text { good }\end{array}$ & $\begin{array}{l}\text { Price } \\
\text { unfair } \\
\text { good }\end{array}$ \\
\hline $\begin{array}{l}\text { No } \\
\text { CoORDINATION }\end{array}$ & $56.94 \%$ & $37.76 \%$ & $5.30 \%$ & $35.50 \%$ & $23.87 \%$ & $40.63 \%$ & 28.61 & 19.23 \\
CoORDINATION & $55.37 \%$ & $39.58 \%$ & $5.05 \%$ & $43.19 \% * *$ & $30.69 \% * *$ & $26.12 \% * * *$ & $27.02^{* *}$ & 18.05 \\
\hline N & 2400 & 2400 & 2400 & 2400 & 2400 & 2400 & 1347 & 929 \\
\hline
\end{tabular}

Notes: ${ }^{*} \mathrm{p}<0.1,{ }^{* *} \mathrm{p}<0.05,{ }^{* * *} \mathrm{p}<0.01$. Significance calculation based on individual level random effects regressions with robust standard errors clustered by subject. Only a dummy variable for the COORDINATION treatment is included as explanatory variable.

Table B.2 : Random effects regressions of type of goods traded, type of goods offered, and market prices in all experiments

\begin{tabular}{|c|c|c|c|c|c|c|}
\hline & $\begin{array}{l}\text { Fair good } \\
\text { traded } \\
(1) \\
\text { Logit }\end{array}$ & $\begin{array}{l}\text { Asymmetric } \\
\text { offer } \\
(2) \\
\text { Logit }\end{array}$ & $\begin{array}{l}\text { Fair/Fair } \\
\text { offer } \\
\text { (3) } \\
\text { Logit }\end{array}$ & $\begin{array}{l}\text { Unfair/Unfair } \\
\text { offer } \\
(4) \\
\text { Logit }\end{array}$ & $\begin{array}{l}\text { Price fair } \\
\text { good } \\
(5)\end{array}$ & $\begin{array}{l}\text { Price unfair } \\
\text { good } \\
(6)\end{array}$ \\
\hline Intercept & $\begin{array}{l}0.2891^{*} \\
(0.1665)\end{array}$ & $\begin{array}{l}-0.4570^{* * *} \\
(0.2092)\end{array}$ & $\begin{array}{l}-0.8445^{* * *} \\
(0.1636)\end{array}$ & $\begin{array}{l}-1.4900^{* * *} \\
(0.1901)\end{array}$ & $\begin{array}{l}37.1941^{* * *} \\
(0.9161)\end{array}$ & $\begin{array}{l}2.1968^{* * *} \\
(1.1879)\end{array}$ \\
\hline COORDINATION & $\begin{array}{l}-0.1023 \\
(0.1849)\end{array}$ & $\begin{array}{l}-0.6972^{* * *} \\
(0.1108)\end{array}$ & $\begin{array}{l}0.4100^{* *} \\
(0.1799)\end{array}$ & $\begin{array}{l}0.5163^{* *} \\
(0.2194)\end{array}$ & $\begin{array}{l}-1.8087^{* *} \\
(.8442)\end{array}$ & $\begin{array}{l}-1.2027 \\
(1.1323)\end{array}$ \\
\hline Period & $\begin{array}{l}0.0061 \\
(0.0078)\end{array}$ & $\begin{array}{l}-0.0039 \\
(0.0072)\end{array}$ & $\begin{array}{l}0.0050 \\
(0.0076)\end{array}$ & $\begin{array}{l}-0.0129 \\
(0.0088)\end{array}$ & $\begin{array}{l}-0.6812^{* * *} \\
(0.0466)\end{array}$ & $\begin{array}{l}-0.5593^{* * *} \\
(0.0474)\end{array}$ \\
\hline $\mathrm{N}$ & 2400 & 1200 & 1200 & 1200 & 1347 & 929 \\
\hline
\end{tabular}

\footnotetext{
${ }^{26}$ Consumer surplus, based on the third-party preferences measured in part 1 of the experiment, equals 142.08 [142.60] in the No COORDINATION [COORDINATION] treatment. Firm profits are equal to 77.50 [76.90] in the No COORDINATION [COORDINATION] treatment. Producer surplus, based on third-party preferences, equals 96.02 [94.66] in the No COORDINATION [COORDINATION] treatment. There are no significant differences.
} 
Table B.3: Consumer behavior in all experiments

\begin{tabular}{|c|c|c|}
\hline & $\begin{array}{l}\text { Avoiding the } \\
\text { externality } \\
\text { (1) } \\
\text { Logit }\end{array}$ & $\begin{array}{c}\text { Fair good } \\
\text { purchased } \\
(2) \\
\text { Logit }\end{array}$ \\
\hline Intercept & $\begin{array}{c}-06233^{* * *} \\
(0.2392)\end{array}$ & $\begin{array}{c}1.1392^{*} \\
(0.6702)\end{array}$ \\
\hline Period & $\begin{array}{c}0.0088 \\
(0.0165)\end{array}$ & $\begin{array}{l}-0.0487^{*} \\
(0.0260)\end{array}$ \\
\hline 3rdPartyPref & $\begin{array}{c}0.0509 * * * \\
(0.0061)\end{array}$ & $\begin{array}{c}0.1311^{* * *} \\
(0.0267)\end{array}$ \\
\hline COORDINATION & $\begin{array}{l}-0.2005 \\
(0.2138)\end{array}$ & $\begin{array}{l}-0.9319 \\
(0.6029)\end{array}$ \\
\hline PricediffFU & - & $\begin{array}{c}-0.2909^{* * *} \\
(0.0494)\end{array}$ \\
\hline $\mathrm{N}$ & 2223 & 728 \\
\hline
\end{tabular}

Notes: The dependent variable in (1) takes value 1 if the fair good or no good is bought. Specification (2) restricts the analysis to observations where the consumer receives offers for both types of good. The dependent variable in (2) takes value 1 if the fair good is bought and 0 otherwise. PricediffFU is the difference in prices between the fair and unfair good when both goods are offered. Period takes values from 1 to 24. COORDINATION takes value 1 for the COORDINATION treatment. Observations where participants revealed inconsistent third-party preferences are excluded. The models allow for individual level random effects. Robust standard errors in parentheses (clustered by subject). ${ }^{*} p<0.1,{ }^{* *} p<0.05,{ }^{* * *} p<0.01$

Table B.4 : Firms' behavior all experiments

\begin{tabular}{|c|c|c|c|c|c|}
\hline & $\begin{array}{c}\text { Fair good } \\
\text { offered } \\
(1) \\
\text { Logit } \\
\end{array}$ & $\begin{array}{c}\text { Fair good } \\
\text { offered } \\
(2) \\
\text { Logit } \\
\end{array}$ & $\begin{array}{c}\text { Unfair/fair } \\
\text { offer } \\
\text { (3) } \\
\text { Logit } \\
\end{array}$ & $\begin{array}{c}\text { Fair/Fair } \\
\text { offer } \\
(4) \\
\text { Logit }\end{array}$ & $\begin{array}{c}\text { Unfair/Unfair } \\
\text { offer } \\
\text { (5) } \\
\text { Logit }\end{array}$ \\
\hline Intercept & $\begin{array}{c}-1.9697^{* * *} \\
(0.0087)\end{array}$ & $\begin{array}{c}-3.8904^{* * *} \\
(0.5294)\end{array}$ & $\begin{array}{c}-1.3364^{* *} \\
(0.5727)\end{array}$ & $\begin{array}{c}0.8164^{* * *} \\
(0.2621)\end{array}$ & $\begin{array}{c}0.5993^{*} \\
(0.3140)\end{array}$ \\
\hline Period & $\begin{array}{c}0.0117 \\
(0.0087)\end{array}$ & $\begin{array}{c}0.0179 \\
(0.0172)\end{array}$ & $\begin{array}{l}0.0538 * \\
(0.0301)\end{array}$ & $\begin{array}{c}0.0078 \\
(0.0171)\end{array}$ & $\begin{array}{c}-0.0146 \\
(0.0093)\end{array}$ \\
\hline 3rdPartyPref & $\begin{array}{c}0.0839 * * * \\
(0.0089)\end{array}$ & $\begin{array}{c}0.0321 \\
(0.0205)\end{array}$ & - & - & $\begin{array}{c}-0.0512^{* * *} \\
(0.0079)\end{array}$ \\
\hline 3rdPartyPrefOther & - & $\begin{array}{c}0.0117 \\
(0.0078)\end{array}$ & - & - & $\begin{array}{c}-0.0372^{* * *} \\
(0.0054)\end{array}$ \\
\hline COORDINATION & $\begin{array}{c}0.0719 \\
(0.2880)\end{array}$ & - & $\begin{array}{l}-0.5045 \\
(0.5627)\end{array}$ & $\begin{array}{c}0.2166 \\
(0.2648)\end{array}$ & $\begin{array}{l}0.5203^{* *} \\
(0.2603)\end{array}$ \\
\hline Agreement & - & $\begin{array}{c}0.8071^{* * *} \\
(0.3102)\end{array}$ & - & - & - \\
\hline $\mathrm{N}$ & 4473 & 2068 & 91 & 333 & 1658 \\
\hline
\end{tabular}

Notes: The dependent variable in (1) and (2) takes value 1 if the fair good is offered. Period takes values from 1 to 24. Agreement in (2) takes value 1 if firms reach an agreement in the COORDINATION treatment. COORDINATION takes value 1 for the COORDINATION treatment. (3) is restricted for observations where both firms in the same market are unconditionally selfish i.e. 3rdPartyPref=2.1875. Specification (4) is restricted for observations where both firms in the same market are unconditionally altruistic i.e. 3rdPartyPref=43.75. Specification (5) is restricted to the remaining observations. Observations where participants revealed inconsistent third-party preferences are excluded. The models allow for individual level random effects. Robust standard errors in parentheses (clustered by subject). * $p<0.1$, ${ }^{* *} p<0.05,{ }^{* * *} p<0.01$. 


\section{Appendix C: Instructions}

\section{Instructions Experiment 1 and 3}

Welcome to the experiment!

The instructions are simple, and if you follow them carefully, you might be able to earn money for yourself and another participant in the lab. Both what you and the other participant earn depends on the decisions you make and on the decisions of the others. You will be privately paid at the end of the experiment.

Earnings in the experiment will be denoted by francs. For every 10 francs you earn for yourself in this experiment, you will receive 1 euro.

We ask that you do not communicate with other people during the experiment. Please refrain from verbally reacting to events that occur during the experiment. This is very important.

Raise your hand when you have a question and one of the experimenters will come to your desk.

\section{Structure of the experiment}

The experiment consists of two parts. Part 2 will be explained after we have finished part 1 .

In part 1 , you will be asked to make 10 decisions. In part 2 , you will be asked to make decisions in 24 rounds. Only one of the 10 decisions in part 1 or one of the 24 rounds of part 2 will be randomly selected for payment at the completion of the experiment. Payment will be made to you in private.

\section{Instructions Part 1}

\begin{tabular}{|c|c|c|c|c|c|c|c|c|c|}
\hline & & & Option A & & & & Option B & & \\
\hline 1 & 0 & The other participant 80 & You 12 & 125 & 1 & 0 & The other participant 0 & You & 130 \\
\hline 2 & 0 & The other participant 80 & You 12 & 120 & 2 & 0 & The other participant 0 & You & 130 \\
\hline 3 & 0 & The other participant 80 & You 11 & 115 & 3 & 0 & The other participant 0 & You & 130 \\
\hline 4 & 0 & The other participant 80 & You 11 & 110 & 4 & 0 & The other participant 0 & You & 130 \\
\hline 5 & O & The other participant 80 & You 10 & 105 & 5 & 0 & The other participant 0 & You & 130 \\
\hline 6 & ○ & The other participant 80 & You 10 & 100 & 6 & O & The other participant 0 & You & 130 \\
\hline 7 & 0 & The other participant 80 & You 99 & 95 & 7 & 0 & The other participant 0 & You & 130 \\
\hline 8 & O & The other participant 80 & You $9 c$ & 90 & 8 & 0 & The other participant 0 & You & 130 \\
\hline 9 & ○ & The other participant 80 & You 85 & 85 & 9 & 0 & The other participant 0 & You & 130 \\
\hline 10 & 0 & The other participant 8 & You 8 & 80 & 10 & 0 & The other participant 0 & You & 130 \\
\hline
\end{tabular}

The options refer to payments to you and one of the other participants in this experiment. For each option, two amounts will be displayed: one amount that you will receive yourself, and one amount that another participant will receive. This other participant is one that we will randomly choose. This other participant will remain anonymous to you. 
Recall that only one of the 10 decisions in this part or one of the 24 rounds of part 2 will be randomly selected for payment at the completion of the experiment. If one of the decisions in this part is selected, all participants will be randomly matched into pairs. In each pair, one participant will be randomly chosen, with a probability of $50 \%$, to be the Proposer, and the other will be the Receiver.

If you are chosen to be the Proposer, you will receive the amount you decided to receive in that chosen decision and your paired Receiver will receive the amount you decide to give to "the other participant". Your paired Receiver's decisions in part 1 will have no influence at all.

\section{Questions}

To ensure that these instructions have been understood, we would like you to fill in the blanks into the following statements by indicating how many francs both yourself and the other would obtain if the following choices were made in the randomly selected rows:

1) If you choose option $A$ in row 1 :

You:

The Other:

2) If you choose option $B$ in row 4 :

You:

The Other:

\section{Instructions Part 2}

This part consists of 24 rounds. In every round, you will be asked to make decisions about the sale and purchase of goods in markets. Recall that only one of the 24 rounds of this part or one of the 10 decisions in the previous part will be selected randomly at the completion of the experiment for payment.

\section{Markets}

In every round, you will be a member of a group. This group consists of you and three other people. Two of you will play the role of sellers. A third group member is a buyer. The remaining group member is passive: He or she can neither sell nor buy. However, he/she can incur losses when the sellers and the buyer in his/her group trade.

The four group members will be randomly assigned to one of these roles at the beginning of the experiment. The group composition is unknown to you and to other participants. You will not know who is in your group. Others will not know whether you are in their group. In addition, we will make new groups in every round. Thus, the members of your group will change from round to round.

There are two possible goods that a seller can produce: a fair and an unfair good. When the buyer buys a fair product, the passive group member will obtain 70 francs. In contrast, the passive group 
member will lose all of its 70 francs when the buyer buys an unfair product. If no good is traded, the passive group member obtains 70 francs.

From one round to the next, buyers and sellers sometimes switch roles. So, when in one round you are a seller, in the next, you may be a buyer. The role of the passive group member is fixed throughout the experiment. In other words, once you are assigned the role of passive group member in the first round of the experiment, you keep this role in all following rounds.

\section{Sellers}

In each round the two sellers have to make two choices. First they decide what kind of good they would like to sell: a fair or an unfair good. Then they choose a price at which they would like to sell their good to the buyer.

(Here text for Coordination treatment; see below)

Once both sellers have decided which good they would like to sell, they will be informed of the decision of the other seller in the market. Only then will the sellers choose the price at which they would like to sell their good. The price must be between 0 and 100 francs. At the end of each round the sellers will be able to observe the price chosen by the other seller and whether a transaction took place.

If a seller sells a good, he or she obtains the price he or she posted. If a seller sells the fair good to the buyer, the seller must pay a production cost of 15 francs. A seller has zero production costs when selling the unfair good, or when not selling anything.

In addition to payoffs achieved through transactions, the sellers will receive 70 francs in each round regardless of whether they make a transaction or not.

\section{Buyers}

The buyer may choose to buy only one good from one of the two sellers. The buyer may also decide not to purchase at all. Before making a choice, the buyer will be informed of the price of the two goods and whether the goods are fair or unfair. If a buyer purchases either good, he or she will receive a payoff of 80 francs minus the price he or she pays to the seller offering the good. A buyer will also receive an additional 70 francs regardless of whether they purchase a good or not.

Recall that when the buyer buys a fair product, the passive group member will obtain 70 francs. In contrast, the passive group member will lose all of his/her 70 francs when the buyer buys an unfair product. If no good is traded, the passive group member obtains 70 francs. 


\section{Questions}

To ensure that these instructions have been understood we would like you to fill in the blanks into the following statements by indicating how many francs both yourself and the passive group member would obtain if the following choices were made in the randomly selected round.

1) Suppose you are a seller. You offer a fair good at the price 45 francs that is purchased by the buyer. The payoffs are:

You: $\quad$ The passive group member: Other Seller: Buyer:

2) Suppose you are a buyer. You buy an unfair good at the price of 5 francs. The payoffs are: You: The passive group member:

Seller you chose: Other seller:

\section{Formulas that may help you to answer the questions:}

Profits buyer when not buying the product: 70

Profits buyer when buying a product: $70+(80$ - price $)$

Seller when not selling the product: 70

Seller when selling the FAIR product: $70+$ price - 15

Seller when selling the UNFAIR product: $70+$ price

Money for the passive group member when a FAIR product is bought or no transaction: 70

\section{Instructions Experiment 2}

Welcome to the experiment!

The instructions are simple, and if you follow them carefully, you might be able to earn money for the purpose of environmental protection, as well as earn an amount of money for yourself. Both what you earn and what you decide to leave as a donation to environmental protection depends on the decisions you make and on the decisions of the others. You will be privately paid at the end of the experiment.

Earnings in the experiment will be denoted by francs. For every 10 francs you earned for yourself in this experiment, you will receive 1 euro. At the end of the experiment, we will donate the francs that were designated for environmental protection to CarbonFund.org. CarbonFund.org is an organization that allows individuals to offset their carbon footprint, which includes the emissions from their homes, cars, and air travel. In particular, for every 10 francs retained for CarbonFund.org, we will donate 1 euro to CarbonFund.org, which allows offsetting about $110 \mathrm{~kg}$ of CO2. In addition to this, all participants will receive a 7.50 euro show up fee for attending the experiment. 
We ask that you do not communicate with other people during the experiment. Please refrain from verbally reacting to events that occur during the experiment. This is very important.

Raise your hand when you have a question and one of the experimenters will come to your desk.

\section{Structure of the experiment}

The experiment consists of two parts. Part 2 will be explained after we have finished part 1 .

In part 1 , you will be asked to make 10 decisions. In part 2 , you will be asked to make decisions in 24 rounds. Only one of the 10 decisions in part 1 or one of the 24 rounds of part 2 will be randomly selected for payment at the completion of the experiment. Payment will be made to you in private. Contributions to CarbonFund.org will remain anonymous. At the end of the experiment, we will publicly donate the total amount raised in this experiment to CarbonFund.org. Other participants will not know what your personal donations were.

\section{Instructions Part 1}

\begin{tabular}{|c|c|c|c|c|c|c|c|}
\hline \multicolumn{4}{|c|}{ Option A } & \multicolumn{4}{|c|}{ Option B } \\
\hline 1 & $\circ$ & CarbonFund. org 80 & You 125 & 1 & 0 & CarbonFund. org 0 & You 130 \\
\hline 2 & $\circ$ & CarbonFund. org 80 & You 120 & 2 & $\circ$ & CarbonFund. org 0 & You 130 \\
\hline 3 & $\circ$ & CarbonFund. org 80 & You 115 & 3 & ○ & CarbonFund.org 0 & You 130 \\
\hline 4 & $\circ$ & CarbonFund. org 80 & You 110 & 4 & ○ & CarbonFund.org 0 & You 130 \\
\hline 5 & $\circ$ & CarbonFund. org 80 & You 105 & 5 & ○ & CarbonFund.org 0 & You 130 \\
\hline 6 & $\circ$ & Carbonfund. org 80 & You 100 & 6 & ○ & CarbonFund.org 0 & You 130 \\
\hline 7 & $\circ$ & CarbonFund. org 80 & You 95 & 7 & 0 & CarbonFund. org 0 & You 130 \\
\hline 8 & 0 & CarbonFund.org 80 & You 90 & 8 & $\circ$ & CarbonFund.org 0 & You 130 \\
\hline 9 & $\circ$ & CarbonFund. org 80 & You 85 & 9 & ○ & CarbonFund. org 0 & You 130 \\
\hline 10 & ○ & CarbonFund. org 80 & You 80 & 10 & ○ & CarbonFund. org 0 & You 130 \\
\hline
\end{tabular}

In this stage of the experiment you will be asked to make 10 choices from the table on your screen. You must choose between Option A and Option B in each of the 10 choices. These choices differ in the amount of francs that you apportion to yourself and the amount that you leave for CarbonFund.org. If one of the choices in this part is selected for payment at the end of the experiment, your show-up fee (7.5 euros) is added to the amount presented in the table.

\section{Questions}

To ensure that these instructions have been understood, we would like you to fill in the blanks into the following statements by indicating how many francs both both yourself and CarbonFund.org would obtain:

1) If you choose option $A$ in row 1 :

You: CarbonFund.org: 
2) If you choose option B in row 4:

You: $\quad$ CarbonFund.org:

\section{Instructions Part 2}

This part consists of 24 rounds. In every round, you will be asked to make decisions about the sale and purchase of goods in markets. Recall that only one of the 24 rounds of this part or one of the 10 decisions in the previous part will be selected randomly at the completion of the experiment for payment.

\section{Markets}

In every round, you will be a member of a group. This group consists of you and two other people. Two of you will play the role of sellers. The remaining member is a buyer. The three group members will be randomly assigned to one of these roles at the beginning of each round. The group composition is unknown to you and to other participants. You will not know who is in your group. Others will not know whether you are in their group. In addition, we will make new groups in every round. Thus, the members of your group will change from round to round.

There are two possible goods that a seller can produce: a fair and an unfair good. When the buyer buys a fair product, CarbonFund.org will obtain 70 francs for carbon offset. In contrast, CarbonFund.org will lose all of its 70 francs when the buyer buys an unfair product. If no good is traded, CarbonFund.org obtains 70 francs.

\section{Sellers}

In each round the two sellers have to make two choices. First they decide what kind of good they would like to sell: a fair or an unfair good. Then they choose a price at which they would like to sell their good to the buyer.

\section{(Here text for Coordination treatment; see below)}

Once both sellers have decided which good they would like to sell, they will be informed of the decision of the other seller in the market. Only then will the sellers choose the price at which they would like to sell their good. The price must be between 0 and 100 francs. At the end of each round the sellers will be able to observe the price chosen by the other seller and whether a transaction took place.

If a seller sells a good, he or she obtains the price he or she posted. If a seller sells the fair good to the buyer, the seller must pay a production cost of 15 francs. A seller has zero production costs when selling the unfair good, or when not selling anything.

In addition to payoffs achieved through transactions, the sellers will receive 70 francs in each round regardless of whether they make a transaction or not. 


\section{Buyers}

The buyer may choose to buy only one good from one of the two sellers. The buyer may also decide not to purchase at all. Before making a choice, the buyer will be informed of the price of the two goods and whether the goods are fair or unfair. If a buyer purchases either good, he or she will receive a payoff of 80 francs minus the price he or she pays to the seller offering the good. A buyer will also receive an additional 70 francs regardless of whether they purchase a good or not.

Recall that when the buyer buys a fair product, CarbonFund.org will obtain 70 francs for carbon offset. In contrast, CarbonFund.org will lose all of its 70 francs when the buyer buys an unfair product. If no good is traded, CarbonFund.org obtains 70 francs.

\section{Questions}

To ensure that these instructions have been understood we would like you to fill in the blanks into the following statements by indicating how many francs both yourself and the passive group member would obtain if the following choices were made in the randomly selected round.

1) Suppose you are a seller. You offer a fair good at the price 45 francs that is purchased by the buyer. The payoffs are:

You: CarbonFund.org: Other Seller: Buyer:

2) Suppose you are a buyer. You buy an unfair good at the price of 5 francs. The payoffs are:

You:

CarbonFund.org: $\quad$ Seller you chose:

Other seller:

\section{Formulas that may help you to answer the questions:}

Profits buyer when not buying the product: 70

Profits buyer when buying a product: $70+(80$ - price $)$

Seller when not selling the product: 70

Seller when selling the FAIR product: $70+$ price -15

Seller when selling the UNFAIR product: $70+$ price

Money for CarbonFund.org when a FAIR product is bought or no transaction: 70 
The two sellers are allowed to make an agreement on which good they would like to produce. For this purpose, both sellers can make a proposal to the other seller. The table below presents the possible proposals that a seller can make:

\begin{tabular}{|c|l|l|l}
\hline \multirow{2}{*}{$\begin{array}{c}\text { My } \\
\text { product }\end{array}$} & Fair Good & Both produce fair goods & $\begin{array}{l}\text { I produce the fair good, the } \\
\text { other seller produces the } \\
\text { unfair good }\end{array}$ \\
\cline { 2 - 4 } & Unfair Good & $\begin{array}{l}\text { I produce the unfair good, } \\
\text { the other seller produces } \\
\text { the fair good }\end{array}$ & Both produce unfair goods \\
\cline { 2 - 4 } & & & \\
\hline
\end{tabular}

The computer randomly chooses one seller to make the first proposal. If the other seller rejects this proposal, the other seller can make a new proposal. Once a seller accepts the other seller's proposal, each offers the agreed upon product to the buyer.

If both sellers' proposals are rejected, both sellers will have to choose the product type and the price independently. If this is the case, they will only find out which good the other seller has chosen to sell after both sellers have made their choices regarding the product type. After both the sellers have made their choice of good the sellers have to choose a price at which to sell their good.

\section{Additional text in Coordination treatment in Experiment 3:}

The two sellers are allowed to make an agreement on both offering the fair good. For this purpose, both sellers are asked whether they agree that both offer the fair good. Both sellers must answer "yes" or "no". If both choose "yes", each offers the fair product to the buyer. If one or two sellers chooses "no", both sellers will choose the product type independently. In this case, they will only find out which good the other seller has chosen to sell after both sellers have made their choices regarding the product type.

After both the sellers have made their choice of good (with or without agreement), the sellers have to choose a price at which to sell their good. 